Journal of

Molecular Microbiology

and Biotechnology
J Mol Microbiol Biotechnol 2008;14:176-192

DOI: $\underline{10.1159 / 000109945}$

Published online: October 15, 2007

\title{
New Insights into the Role of Sigma Factor RpoS as Revealed in Escherichia coli Strains Lacking the Phosphoenolpyruvate:Carbohydrate Phosphotransferase System
}

\author{
Noemí Flores $^{a}$ Adelfo Escalante ${ }^{a}$ Ramón de Anda ${ }^{a}$ José Luis Báez-Viveros ${ }^{a}$ \\ Enrique Merino $^{b}$ Bernardo Franco ${ }^{c}$ Dimitris Georgellis ${ }^{c}$ Guillermo Gosset ${ }^{a}$ \\ Francisco Bolívar ${ }^{a}$ \\ Departamentos de a Ingeniería Celular y Biocatálisis y ${ }^{b}$ Microbiología Molecular, Instituto de Biotecnología/UNAM, \\ Cuernavaca, and ' ${ }^{\mathrm{D}}$ Departamento de Genética Molecular, Instituto de Fisiología Celular/UNAM, México, México
}

\section{Key Words}

Phosphoenolpyruvate:carbohydrate phosphotransferase system · RpoS · SpoT · Gpp · ppGpp · Carbon limitation • Adaptive evolution

\begin{abstract}
It has been demonstrated that about $10 \%$ of the Escherichia coli genes are under direct or indirect control of RpoS. Therefore, Weber et al. [2005] proposed that this sigma subunit should be considered a second vegetative sigma factor under non-optimal growth conditions. In this report we demonstrate that in the phosphoenolpyruvate:carbohydrate phosphotransferase system-deficient (PTS-) derivatives, PB11 and PB12 of strain JM101 that permanently grow slowly on glucose, the inactivation of rpoS resulted in decreased growth rates of 50 and $10 \%$, respectively. Real-time PCR (RT$\mathrm{PCR}$ ) analysis confirmed the important role of this sigma factor in the PTS ${ }^{-}$strains and allowed the identification of 19 genes including almost all the glycolytic genes, not previously reported, to be at least partially dependent on RpoS. The transcription level of gpp, spoT, ppa and $n d k$ whose products are involved in ppGpp metabolism was upregulated in strain PB12 as compared to the parental strains PB11 and JM101. In the PTS ${ }^{-}$strains, at least three of these genes (gpp,
\end{abstract}

spoT and ppa) were mainly or partially regulated by RpoS which is known to require ppGpp for activation, while only gpp was highly RpoS-dependent in the parental $\mathrm{PTS}^{+}$strain JM101. The role of RpoS in the transcription of these genes was analyzed and evidence that the expression of this group of genes could be regulated by a common factor in addition to RpoS was discussed.

Copyright $\odot 2007$ S. Karger AG, Basel

\section{Introduction}

In Escherichia coli, the primary response to glucose limitation $\left(\mu=0.1 \cdot h^{-1}\right)$, known as hunger or scavenging response, is the activation of a group of genes that allow high affinity uptake of different carbohydrates as well as other carbon sources such as acetate [Hengge-Aronis, 1996, 2002; Notley-McRobb and Ferenci, 1996, 2001]. These nutrient-specific systems are part of the CRP regulon for the use of alternative carbon sources [Gosset et al., 2004]. The E. coli genome encodes several sigma factors that enable the use of alternative promoter sequences, some of which can transcribe the same gene in different metabolic and stress conditions. The rpoS gene codes for the sigma factor $S$ or RpoS which has been involved in the

\section{KARGER}

Fax +4161306 1234 E-Mail karger@karger.ch www.karger.com

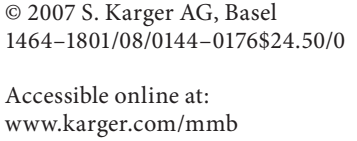

Francisco Bolívar

Departamentos de Ingeniería Celular y Biocatálisis

Instituto de Biotecnología/UNAM

Cuernavaca, Morelos 62271 (México)

Tel. +52 777311 4703, Fax +52 777329 1601, E-Mail noemi@ibt.unam.mx 
transcription of several genes expressed in the stationary phase and on glucose-limited growth conditions. It has been reported that while the cellular sigma S concentration is the highest in early stationary phase cells, exponentially growing cells in minimal medium maintain low levels of this sigma factor [Lange and Hengge-Aronis, 1994; Notley-McRobb and Ferenci, 1996; Hengge-Aronis, 2002]. Interestingly, recent genome-wide expression analysis by Weber et al. [2005] indicates that up to $10 \%$ of the E. coli genes are under direct or indirect control of RpoS. Therefore, these authors have proposed that this sigma subunit should be considered a second vegetative sigma factor with major impact not only on stress tolerance but on the entire cell physiology under non-optimal growth conditions.

RpoS-dependent promoters require ppGpp to induce gene transcription even in the presence of high levels of sigma S [Kvint et al., 2000]. Under favorable growth conditions a steady-state level of pppGpp and ppGpp is maintained in the cytosol mainly by the activity of three enzymes: RelA, SpoT and Gpp. RelA and SpoT synthesize pppGpp while Gpp transforms this metabolite into ppGpp [Lengeler et al., 1999; Chatterji and Ojha, 2001]. In a relA-spoT double mutant, where no ppGpp is produced, the cellular content of sigma $S$ is greatly decreased indicating that the transcription of the rpoS gene depends on the presence of ppGpp [Lange et al., 1995]. It is known that ppGpp alarmone levels are increased following the depletion of amino acids (triggering the stringent response), upon starvation of carbon or nitrogen, as well as in cells growing slowly in a chemostat [Notley-McRobb and Ferenci, 1996; Lengeler et al., 1999; Teich et al., 1999; Hengge-Aronis, 2002].

Many regulons whose transcription is controlled by alternative sigma factors, such as sigma $\mathrm{S}$, are poorly induced in cells lacking the ppGpp alarmone. In fact, the absence of this alarmone prevents cell growth in minimal medium [Cashel et al., 1996]. An in vitro transcription/ competition assay with reconstituted RNA polymerase showed that addition of ppGpp reduces the ability of wild-type sigma 70 to compete with sigma $S$ for its binding to the RNA polymerase core. Similarly, an in vivo competition assay demonstrated that the ability of sigma S to compete with sigma 70 is diminished in cells lacking ppGpp. Consistently, the fraction of sigma $S$ bound to the RNA polymerase core is drastically reduced in ppGppdeficient cells. Thus, stringent and carbon limitation responses apparently encompass a mechanism that alters the relative competitivity of sigma factors for the RNA polymerase core [Cashel et al., 1996; Maeda et al., 2000;
Baker et al., 2001a, b; Chatterji and Ojha, 2001; HenggeAronis, 2002; Jishage et al., 2002]. In addition, it has been reported that ppGpp acts on transcription initiation, inhibiting the formation of the open promoter complex and thereby transcript elongation. This failure in gene transcription may increase the availability of RNAP holoenzyme, favoring in turn the binding of RpoS versus RpoD to the RNA polymerase core. As a consequence of this, the RpoS-dependent transcription is activated. Hence, an increase in ppGpp alarmone favors the transcription of sigma S-dependent promoters [Wagner, 2002; Artsimovitch et al., 2004].

In E. coli, glucose transport and phosphorylation are mainly dependent on the phosphoenolpyruvate:carbohydrate phosphotransferase system (PTS) [Postma et al., 1996; Saier, 2002]. In a strain lacking PTS, such as PB11, the cells grow very slowly $\left(\mu=0.1 \cdot h^{-1}\right)$ in minimal medium on glucose as the sole carbon source. This is explained by the fact that they have lost most of their glucose transport capacity and therefore, they permanently sense very low levels of intracellular glucose or glucose6-phosphate even in the presence of a high glucose concentration in the medium. As a result of this type of growth under non-optimal conditions, these cells induce the synthesis of galactose. This molecule in turn inactivates the galactose repressor causing the upregulation of galP, the gene coding for the GalP permease responsible for glucose uptake in this strain [Death and Ferenci, 1994; Notley and Ferenci, 1996; Hua et al., 2004; Flores S et al., 2002, 2005; Flores $\mathrm{N}$ et al., 2005; Weber et al., 2005]. It has been reported that in a strain lacking the $\mathrm{cr} r$ gene such as $\mathrm{PB} 11$, the translation of the rpoS mRNA is no longer repressed by the IIA ${ }^{\mathrm{Glc}}$ component of PTS, allowing higher levels of RpoS protein even during the exponential growth phase [Ueguchi et al., 2001; Flores N et al., 2005]. Therefore, it is expected that this strain, growing in non-optimal nutrient conditions, may increase the synthesis of ppGpp as a starvation-stress signal since RpoS, in conjunction with ppGpp, is responsible for its own synthesis and high concentrations of this alarmone are required for RpoS-RNA polymerase transcription [Lange et al., 1995; Lengeler et al., 1999; Kvint et al., 2000; Baker et al., 2001a, b; Hengge-Aronis, 2002]. In agreement with these considerations, it has been previously reported that the transcription of rpoS, poxB, talA and $t k t B$, members of the RpoS modulon, is upregulated in PB11, as compared to the wild-type strain JM101 when growing on glucose as the only carbon source [Weber et al., 2005; Flores N et al., 2005]. 
Strains PB12 and PB13 were derived from PB11 in an adaptive evolution fermentation experiment. It has been published that PB12 carries at least two mutations that allow higher rates of glucose transport and growth [Flores N, 1995, Flores N et al., 1996]. Moreover, it has been reported that in the PTS $^{-}$strain PB12, a fraction of the phosphoenolpyruvate that is not consumed for glucose transport, could be redirected into the synthesis of aromatic compounds [Flores $\mathrm{N}$ et al., 1996; Gosset et al., 1996; Báez et al., 2001, 2004]. Due to this biotechnological potential, we have been interested in characterizing these and other PTS $^{-}$strains [Flores N et al., 2004; de Anda et al., 2006]. In PB12, which grows faster on glucose than PB11 $\left(\mu=0.4 v s .0 .1 \cdot h^{-1}\right)$, the carbon flux distribution is modified at various portions of the central carbon metabolism as compared to the parental strains. It has also been shown that $g l k$, pgi, lpd as well as many other genes coding for TCA enzymes are upregulated in PB12 as compared to the parental strains [Flores N, et al., 2005].

In the present contribution, we provide and discuss evidence showing that PB12, as well as PB13, carry a point mutation in the rpoS gene that, in principle, should generate a truncated RpoS polypeptide. However, these strains also carry the supE gene that may suppress this mutation, at least partially. This last proposition is supported by the fact that in PB12 the transcription levels of many genes that are members of the RpoS modulon are still upregulated but at different and lower levels of those found in PB11. Furthermore, knockout inactivation of rpoS in PB11 and PB12 by insertion of a $\mathrm{Tc}^{\mathrm{r}}$ cassette differentially decreases the transcription of previously reported rpoS-dependent genes and many others, thus indicating an important role of this sigma subunit in both $\mathrm{PTS}^{-}$strains. Finally, the transcription level of a group of genes involved in ppGpp synthesis and degradation are 3- to 5-fold upregulated in PB12 and PB13 as compared to JM101 and PB11 strains. The role of RpoS in the transcription of these genes is discussed and evidence that the expression of this group of genes may be regulated by a common factor in addition to RpoS, is presented.

\section{Results and Discussion}

\section{Detection of a Point Mutation in the rpoS Gene in} Strains PB12 and PB13

It has been reported that $E$. coli strains can adapt their metabolism to higher growth rates on specific carbon sources as a result of specific mutations [Raghunathan and Palsson, 2003]. During the process utilized for the selection of rapidly growing strains $\mathrm{PB} 12$ and $\mathrm{PB} 13$ from the PTS ${ }^{-}$PB11 strain, at least two non-cotransducible mutations were selected that allowed PB12 to consume glucose in the absence of PTS at a higher rate than PB11 [Flores N, 1995; Flores N et al., 1996].

The nucleotide sequences of several genes of PB12 and PB13 have been previously determined and only a single point mutation was detected in the $\operatorname{arcB}$ gene of PB12 [Flores $\mathrm{N}$ et al., 2005]. A second mutation in these strains located at the rpoS gene was identified and characterized in the present contribution. It has been reported that the appearance of mutations at the rpoS gene is a frequent event when $E$. coli grows slowly $\left(\mu=0.1 \cdot \mathrm{h}^{-1}\right)$ in glucoselimited controlled conditions [Notley-McRobb et al., 2002; Ferenci, 2003; King et al., 2006]. The mutation found in PB12 occurred at position 98 and changed the coding triplet TCG to the stop codon TAG. As a result of this point mutation a truncated 32 -amino acid residue polypeptide should be produced instead of the original 228-residue wild-type protein. However, it is known that the parental strain JM101 carries a supE mutation that suppresses stop codon amber mutations [Bolívar et al., 1977]. Therefore, the translation of rpoS mRNA might produce functional RpoS for the transcription of RpoSdependent genes. Evidence will be presented showing that the rpoS gene is at least partially functional since the transcription of RpoS-dependent genes is still present in PB12 (and PB13, data not shown) as shown in the next section. Finally, inactivation of rpoS by insertion of a $\mathrm{Tc}^{\mathrm{r}}$ cassette in PB12 and in the parental PB11 generated strains PB12 rpoS::: $\mathrm{Tc}^{\mathrm{r}}$ and PB11 rpoS::Tc ${ }^{\mathrm{r}}$, respectively. Inactivation of rpoS by this method clearly demonstrates, as will be presented below, that there is sufficient RpoS activity in PB12 because the transcription of many RpoScontrolled genes was higher in the parental strains than in the rpoS::Tc ${ }^{\mathrm{r}}$ derivative mutants. Nevertheless, from these results it cannot be concluded that the point mutation in PB12 is completely suppressed. It can be speculated that this point mutation was selected to reduce the amount of active RpoS, especially if it was not completely suppressed, thus allowing or facilitating the preferential transcription of certain RpoS-dependent genes by RpoD. This in turn could allow a faster growth on glucose to the cell carrying this mutation. Furthermore, as will be presented below, an additional mutation could have been selected in PB12 or in a precursor strain that modified, probably reduced, the amount of ppGpp in the cell. This second event could also have contributed to further reducing the transcription capacity of RpoS, favoring growth increase as well. It is important to point out that 
no mutation was detected in the $r p o D$ gene of PB11 and PB12 (data not shown), excluding the possibility of an altered sigma 70 subunit competing with RpoS for the transcription of certain genes.

\section{Transcription Levels of RpoS-Controlled Genes}

The transcription levels of 67 genes, some of which are known to contain RpoS-dependent promoters, were determined by RT-PCR in the strains JM101, PB11, PB12 and their rpoS::Tc ${ }^{\mathrm{r}}$ derivatives (table 1). The expression levels of most of the tested genes in the rpoS::Tc ${ }^{\mathrm{r}}$ derivative of the parental wild-type strain JM101 were not significantly modified as compared to the wild-type strain when cells were growing logarithmically in minimal medium on glucose. Nevertheless, some interesting differences among these strains were observed. Some genes known to be highly RpoS-dependent such as osmY, $p f k A$, talA $t k t B$ were downregulated in JM101 rpoS::Tc ${ }^{\mathrm{r}}$ [Weber et al., 2005]. Moreover, genes not previously reported as part of the RpoS modulon, like fbaA, gpp, ppa and rpoS, were also downregulated. There was a slight upregulation in the transcription of $g a p C-1$ and $g a p C-2$ as well as aceEF and $l p d$ (table 1). If this upregulation is significant, being within the resolution limits of the RT-PCR technique, it is in agreement with results previously published by Rahman et al. [2006] which demonstrated that the transcription of these last three genes is upregulated in an E. coli B $r p o S^{-}$strain when the cells are growing logarithmically on Luria broth (LB).

It has previously been reported that when PB12 and the parental strain PB11 are grown in minimal medium with glucose $(2 \mathrm{~g} / \mathrm{l})$ as the only carbon source, there is an upregulation of certain genes ( $p o x B, r p o S$, tal $A$ and $t k t B$ ) that are part of the RpoS modulon, as compared to the wild-type JM101 [Flores $\mathrm{N}$ et al., 2005]. Results in table 1 show that in PB11 there was a higher level of transcription of most of the highly RpoS-dependent genes [Weber et al., 2005], including rpoS, in comparison with PB12. These results indicate that $\mathrm{PB} 11$ is under severe stress when growing on glucose, as it senses very low internal levels of glucose or glucose-6-phosphate, which resulted in permanent non-optimal growing conditions [Flores $\mathrm{N}$ et al., 2005]. Under these conditions, RpoS-dependent genes are expressed [Weber et al., 2005]. As expected, in the PB11 rpoS:: $\mathrm{Tc}^{\mathrm{r}}$ derivative strain the transcription levels of most of these genes were significantly decreased. For some highly RpoS-dependent genes, such as talA, $t k t B$, galE, gadA, adhP, fbaB, katE and osmY, the transcription levels were decreased more than 10-fold, while in others ( $p f k A, p f k B, p y k A$ and $p o x B$ ) these levels were decreased about 2 - to 3 -fold. There are 19 genes, ace $B A$, aceEF, ack $A$, $a c n B$, acs, eno, fbaA, gapA, gmk, gpmA, gpp, pgi, ppa, $p y k F, s f c A, s p o T$, and $t p i A$, that have not been classified as part of the RpoS modulon whose transcription levels were also decreased in the PB11 rpoS::Tc ${ }^{\mathrm{r}}$ derivative. Interestingly, many of these genes are involved in central carbon metabolism. In fact, transcription levels of all the glycolytic genes with the exception of $l p d$ and $p g k$ were at least 2-fold downregulated in PB11 rpoS::Tc ${ }^{\mathrm{r}}$ strain as compared to PB11, showing the important role of RpoS in this strain when growing on glucose under these conditions. Transcription levels of the genes involved in the glyoxalate shunt and the acs gene, highly upregulated in PB11, were still, but not as highly, upregulated in the PB11 rpos::Tc ${ }^{r}$ derivative. Finally, the transcription levels of the genes involved in the TCA cycle did not change significantly in this strain as compared to PB11, with the exception of $a c n B$ that was 2 -fold downregulated and the $s d h A B$ genes that were 2 -fold upregulated (fig. 1; table 1). In the case of PB12, rpoS inactivation in the derivative strain PB12 rpoS:: $\mathrm{Tc}^{\mathrm{r}}$ also differentially decreased the transcription of many genes as compared to PB12. The transcription of poxB, tal $A, t k t B, g p p$, katE and $o s m Y$ was downregulated more than 10 -fold. Likewise, the transcription levels of most glycolytic genes ( $p g i, p f k A, p f k B$, $f b a A, t p i A, p y k A$, $p y k F$ and aceEF) were decreased approximately 2 -fold although not all glycolytic genes were downregulated in this strain. Interestingly, the transcription levels of the genes involved in the glyoxalate shunt as well as the acs gene were also downregulated. The higher transcription level of many RpoS-dependent genes in PB12 indicates an active role of this sigma factor in this strain. Finally, the transcription levels of most of the TCA genes was not significantly modified in $\mathrm{PB} 12$ rpoS::Tc ${ }^{\mathrm{r}}$, as compared to PB12, with the exception of $a c n B$ whose transcription was 2 -fold downregulated and the $s d h A B$ genes that were increased approximately 2 -fold (fig. 2 ; table 1). This last result is in agreement not only with the fact that the transcription of the TCA genes are already upregulated in this strain because PB12 carried a mutation in the $\operatorname{arcB}$ gene [Flores $\mathrm{N}$ et al., 2005], but also with the report that the transcription of $s d h$ genes is upregulated in $r p o S^{-}$mutants [Weber et al., 2005].

It is clear that RpoS inactivation exerted various and different effects on the strains analyzed in this report. While rpos inactivation did not modify the specific growth rate $(\mu)$ in the $\mathrm{PTS}^{+}$strain JM101 rpos ${ }^{-}$as com-

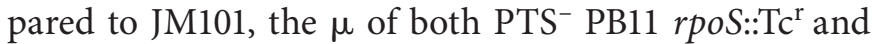
PB12 rpoS::Tc ${ }^{r}$ were diminished by 50 and $10 \%$, respectively, as compared to their parental $r p o S^{+}$strains PB11 
Table 1. Relative transcription levels determined by RT-PCR of several groups of genes from strains JM101, PB11, PB12 and their rpoS::Tc ${ }^{\mathrm{r}}$ derivatives

\begin{tabular}{|c|c|c|c|c|c|c|}
\hline Gene & rpos & $\mathrm{JMrpoS}^{-}$ & PB11 & $11 r p o S^{-}$ & PB12 & $12 r p o S^{-}$ \\
\hline aceA & * & $1.0 \pm 0.1$ & $11.9 \pm 1.2$ & $9.1 \pm 2.8$ & $1.9 \pm 0.2$ & $0.8 \pm 0.1$ \\
\hline aceB & * & $1.0 \pm 0.0$ & $15.6 \pm 2.5$ & $11.0 \pm 2.1$ & $3.7 \pm 0.3$ & $0.8 \pm 0.0$ \\
\hline aceE & * & $1.4 \pm 0.1$ & $0.4 \pm 0.0$ & $0.2 \pm 0.0$ & $1.4 \pm 0.0$ & $0.8 \pm 0.0$ \\
\hline aceF & * & $1.5 \pm 0.1$ & $0.6 \pm 0.0$ & $0.4 \pm 0.1$ & $1.2 \pm 0.0$ & $0.7 \pm 0.0$ \\
\hline $\operatorname{ack} A$ & * & $1.4 \pm 0.0$ & $0.4 \pm 0.1$ & $0.2 \pm 0.0$ & $0.8 \pm 0.0$ & $0.41 \pm 0.0$ \\
\hline $\operatorname{acn} A$ & + & $1.7 \pm 0.1$ & $5.2 \pm 0.6$ & $0.7 \pm 0.1$ & $5.7 \pm 0.2$ & $3.5 \pm 0.3$ \\
\hline$a c n B$ & $*$ & $0.8 \pm 0.1$ & $1.7 \pm 0.4$ & $0.2 \pm 0.0$ & $1.7 \pm 0.4$ & $0.7 \pm 0.0$ \\
\hline acs & $*$ & $0.8 \pm 0.0$ & $5.6 \pm 0.7$ & $4.1 \pm 0.1$ & $8.0 \pm 0.1$ & $3.4 \pm 0.1$ \\
\hline$a d h P$ & + & $1.2 \pm 0.0$ & $9.0 \pm 3.0$ & $0.7 \pm 0.0$ & $3.3 \pm 0.2$ & $0.9 \pm 0.1$ \\
\hline $\operatorname{arc} A$ & + & $1.0 \pm 0.0$ & $1.2 \pm 0.0$ & $0.7 \pm 0.0$ & $1.3 \pm 0.1$ & $1.1 \pm 0.0$ \\
\hline eno & $*$ & $0.9 \pm 0.0$ & $0.5 \pm 0.1$ & $0.2 \pm 0.0$ & $0.5 \pm 0.1$ & $0.4 \pm 0.0$ \\
\hline$f b a A$ & $*$ & $0.3 \pm 0.0$ & $0.9 \pm 0.0$ & $0.3 \pm 0.0$ & $1.1 \pm 0.0$ & $0.4 \pm 0.1$ \\
\hline$f b a B$ & + & $1.0 \pm 0.1$ & $10.6 \pm 1.1$ & $0.9 \pm 0.0$ & $1.1 \pm 0.0$ & $0.9 \pm 0.0$ \\
\hline$f b p$ & & $1.0 \pm 0.2$ & $2.4 \pm 0.7$ & $1.9 \pm 0.4$ & $2.8 \pm 0.1$ & $2.2 \pm 0.1$ \\
\hline fumA & & $1.0 \pm 0.2$ & $3.3 \pm 0.7$ & $2.3 \pm 0.5$ & $3.6 \pm 0.7$ & $3.8 \pm 0.1$ \\
\hline fumB & & $1.2 \pm 0.2$ & $0.3 \pm 0.0$ & $1.2 \pm 0.0$ & $0.4 \pm 0.0$ & $0.4 \pm 0.1$ \\
\hline fumC & + & $0.7 \pm 0.2$ & $4.3 \pm 1.0$ & $2.9 \pm 0.2$ & $3.5 \pm 1.5$ & $2.4 \pm 0.3$ \\
\hline $\operatorname{gad} A$ & + & $1.4 \pm 0.0$ & $18.0 \pm 4.0$ & $1.0 \pm 0.0$ & $1.0 \pm 0.2$ & $0.8 \pm 0.0$ \\
\hline galE & + & $1.0 \pm 0.1$ & $38.8 \pm 6.8$ & $1.4 \pm 0.1$ & $46.6 \pm 6.5$ & $25.0 \pm 2.1$ \\
\hline gapA & $*$ & $0.9 \pm 0.1$ & $0.4 \pm 0.1$ & $0.1 \pm 0.0$ & $1.7 \pm 0.2$ & $1.4 \pm 0.2$ \\
\hline gapC-1 & + & $1.7 \pm 0.1$ & $6.7 \pm 0.1$ & $0.9 \pm 0.1$ & $3.1 \pm 0.1$ & $1.0 \pm 0.2$ \\
\hline gapC-2 & + & $1.8 \pm 0.0$ & $3.9 \pm 0.2$ & $0.7 \pm 0.1$ & $3.2 \pm 0.0$ & $0.9 \pm 0.1$ \\
\hline$g d h A$ & + & $1.1 \pm 0.1$ & $0.5 \pm 0.0$ & $0.4 \pm 0.0$ & $3.5 \pm 0.2$ & $3.0 \pm 0.0$ \\
\hline$g l c B$ & + & $1.0 \pm 0.0$ & $11.7 \pm 1.4$ & $2.5 \pm 0.2$ & $3.7 \pm 0.4$ & $1.8 \pm 0.2$ \\
\hline$g l k$ & & $1.0 \pm 0.1$ & $1.0 \pm 0.0$ & $0.7 \pm 0.1$ & $2.2 \pm 0.1$ & $1.7 \pm 0.1$ \\
\hline gltA & & $0.9 \pm 0.0$ & $0.8 \pm 0.1$ & $1.3 \pm 0.2$ & $1.3 \pm 0.2$ & $1.2 \pm 0.2$ \\
\hline$g m k$ & * & $1.4 \pm 0.1$ & $0.9 \pm 0.1$ & $0.3 \pm 0.0$ & $2.0 \pm 0.2$ & $0.4 \pm 0.0$ \\
\hline$g p m A$ & $*$ & $0.8 \pm 0.1$ & $0.9 \pm 0.0$ & $0.6 \pm 0.1$ & $1.8 \pm 0.0$ & $1.7 \pm 0.3$ \\
\hline$g p m B$ & & $0.9 \pm 0.2$ & $1.5 \pm 0.2$ & $1.6 \pm 0.2$ & $2.7 \pm 0.4$ & $1.9 \pm 0.1$ \\
\hline$g p p$ & $*$ & $0.0 \pm 0.0$ & $1.4 \pm 1.2$ & $0.0 \pm 0.0$ & $5.2 \pm 0.3$ & $0.1 \pm 0.0$ \\
\hline$i c d A$ & & $1.1 \pm 0.1$ & $1.0 \pm 0.1$ & $1.2 \pm 0.0$ & $1.9 \pm 0.0$ & $2.4 \pm 0.0$ \\
\hline katE & + & $1.4 \pm 0.1$ & $24.2 \pm 8.2$ & $2.2 \pm 0.1$ & $7.0 \pm 0.0$ & $0.8 \pm 0.1$ \\
\hline lpd & & $1.4 \pm 0.1$ & $1.1 \pm 0.1$ & $1.3 \pm 0.3$ & $2.0 \pm 0.1$ & $1.7 \pm 0.1$ \\
\hline maeB & & $0.9 \pm 0.0$ & $1.2 \pm 0.2$ & $1.6 \pm 0.0$ & $2.5 \pm 0.0$ & $1.7 \pm 0.0$ \\
\hline malP & + & $1.3 \pm 0.3$ & $5.9 \pm 0.4$ & $0.2 \pm 0.0$ & $1.0 \pm 0.0$ & $0.7 \pm 0.1$ \\
\hline$m d h$ & & $1.3 \pm 0.2$ & $1.2 \pm 0.1$ & $1.4 \pm 0.3$ & $1.8 \pm 0.5$ & $1.4 \pm 0.1$ \\
\hline$n d k$ & & $0.8 \pm 0.1$ & $0.4 \pm 0.0$ & $0.5 \pm 0.0$ & $3.2 \pm 0.1$ & $3.3 \pm 0.1$ \\
\hline osm $Y$ & + & $0.6 \pm 0.0$ & $16.0 \pm 5.2$ & $1.4 \pm 0.1$ & $6.7 \pm 0.3$ & $0.7 \pm 0.1$ \\
\hline$p c k A$ & & $1.0 \pm 0.2$ & $0.8 \pm 0.1$ & $0.9 \pm 0.2$ & $0.8 \pm 0.0$ & $1.3 \pm 0.1$ \\
\hline$p f k A$ & + & $0.4 \pm 0.0$ & $0.3 \pm 0.0$ & $0.0 \pm 0.0$ & $0.5 \pm 0.0$ & $0.2 \pm 0.0$ \\
\hline$p f k B$ & + & $1.2 \pm 0.2$ & $1.2 \pm 0.2$ & $0.4 \pm 0.0$ & $1.9 \pm 0.2$ & $0.9 \pm 0.1$ \\
\hline$p g i$ & $*$ & $0.8 \pm 0.1$ & $1.0 \pm 0.1$ & $0.4 \pm 0.1$ & $6.6 \pm 0.3$ & $3.7 \pm 0.1$ \\
\hline poxB & + & $0.7 \pm 0.1$ & $4.2 \pm 0.3$ & $1.5 \pm 0.1$ & $5.7 \pm 0.5$ & $0.5 \pm 0.0$ \\
\hline$p p a$ & $*$ & $0.6 \pm 0.0$ & $1.0 \pm 0.0$ & $0.5 \pm 0.1$ & $6.1 \pm 1.4$ & $3.8 \pm 0.1$ \\
\hline$p p c$ & & $1.2 \pm 0.0$ & $0.6 \pm 0.1$ & $0.8 \pm 0.1$ & $0.8 \pm 0.0$ & $0.5 \pm 0.1$ \\
\hline$p p s A$ & & $0.6 \pm 0.1$ & $3.7 \pm 0.2$ & $3.3 \pm 0.2$ & $2.4 \pm 0.1$ & $1.1 \pm 0.2$ \\
\hline pta & & $1.8 \pm 0.1$ & $0.7 \pm 0.1$ & $0.6 \pm 0.1$ & $1.5 \pm 0.3$ & $0.6 \pm 0.2$ \\
\hline$p t s G$ & & $1.0 \pm 0.0$ & $1.3 \pm 0.0$ & $1.5 \pm 0.2$ & $1.3 \pm 0.6$ & $2.3 \pm 0.1$ \\
\hline pykA & + & $1.0 \pm 0.2$ & $0.4 \pm 0.0$ & $0.1 \pm 0.0$ & $1.0 \pm 0.0$ & $0.5 \pm 0.1$ \\
\hline pykF & $*$ & $0.8 \pm 0.0$ & $0.8 \pm 0.0$ & $0.2 \pm 0.0$ & $0.9 \pm 0.0$ & $0.5 \pm 0.1$ \\
\hline $\operatorname{rec} G$ & & $4.9 \pm 0.2$ & $0.8 \pm 0.1$ & $1.0 \pm 0.2$ & $6.6 \pm 1.0$ & $3.9 \pm 0.4$ \\
\hline relA & & $1.1 \pm 0.1$ & $1.3 \pm 0.0$ & $0.9 \pm 0.1$ & $1.6 \pm 0.2$ & $1.1 \pm 0.0$ \\
\hline rhlB & & $1.4 \pm 0.1$ & $0.9 \pm 0.0$ & $0.6 \pm 0.0$ & $1.9 \pm 0.1$ & $1.3 \pm 0.0$ \\
\hline$r p o D$ & & $0.7 \pm 0.2$ & $0.8 \pm 0.2$ & $0.7 \pm 0.2$ & $0.9 \pm 0.2$ & $1.1 \pm 0.1$ \\
\hline
\end{tabular}


Table 1 (continued)

\begin{tabular}{|c|c|c|c|c|c|c|}
\hline Gene & rpos & $\mathrm{JMrpos}^{-}$ & PB11 & $11 r p o S^{-}$ & PB12 & $12 r p o S^{-}$ \\
\hline rpos & + & $0.1 \pm 0.0$ & $2.9 \pm 0.1$ & $0.1 \pm 0.0$ & $2.2 \pm 0.2$ & $0.2 \pm 0.0$ \\
\hline rpoz & & $1.3 \pm 0.0$ & $0.9 \pm 0.1$ & $0.7 \pm 0.0$ & $0.8 \pm 0.2$ & $1.2 \pm 0.4$ \\
\hline$s d h A$ & - & $1.0 \pm 0.1$ & $0.9 \pm 0.0$ & $3.7 \pm 0.2$ & $2.0 \pm 0.3$ & $4.0 \pm 0.0$ \\
\hline$s d h B$ & - & $0.9 \pm 0.0$ & $0.8 \pm 0.0$ & $2.2 \pm 0.0$ & $1.7 \pm 0.2$ & $2.4 \pm 0.3$ \\
\hline$s f c A$ & * & $1.8 \pm 0.2$ & $1.9 \pm 0.3$ & $1.1 \pm 0.1$ & $1.7 \pm 0.1$ & $1.0 \pm 0.0$ \\
\hline spot & * & $1.1 \pm 0.1$ & $1.2 \pm 0.2$ & $0.5 \pm 0.1$ & $4.7 \pm 0.2$ & $0.7 \pm 0.1$ \\
\hline sucA & & $1.3 \pm 0.0$ & $1.4 \pm 0.1$ & $1.2 \pm 0.2$ & $1.7 \pm 0.1$ & $1.0 \pm 0.0$ \\
\hline sucC & & $1.4 \pm 0.1$ & $0.9 \pm 0.1$ & $1.3 \pm 0.1$ & $1.6 \pm 0.0$ & $1.5 \pm 0.0$ \\
\hline talA & + & $0.3 \pm 0.0$ & $10.6 \pm 1.9$ & $1.1 \pm 0.3$ & $5.1 \pm 0.7$ & $0.2 \pm 0.0$ \\
\hline talB & & $0.8 \pm 0.0$ & $1.1 \pm 0.1$ & $0.7 \pm 0.0$ & $1.6 \pm 0.0$ & $1.4 \pm 0.2$ \\
\hline$t k t A$ & & $0.7 \pm 0.0$ & $0.5 \pm 0.0$ & $0.3 \pm 0.0$ & $2.4 \pm 0.1$ & $2.1 \pm 0.3$ \\
\hline$t k t B$ & + & $0.4 \pm 0.0$ & $11.6 \pm 0.2$ & $0.3 \pm 0.0$ & $5.7 \pm 0.1$ & $0.7 \pm 0.0$ \\
\hline$t p i A$ & $*$ & $0.2 \pm 0.0$ & $0.5 \pm 0.0$ & $0.2 \pm 0.0$ & $1.8 \pm 0.0$ & $0.3 \pm 0.0$ \\
\hline
\end{tabular}

This table shows the relative transcription levels of the genes involved in different pathways and processes. For each gene in all strains, the transcription level of the gene for the wild-type strain was used as the control to normalize the data using the wild-type RTPCR value for that gene as one. Therefore, data in this table and in figures 1-3 are reported as relative expression levels, compared to the expression level of JM101. The results are the averages of four independent measurements of the RT-PCR expression values for each gene. Two of the values were obtained from one fermentation procedure and the two others from an in- dependent fermentation grown under identical conditions for each strain. The RT-PCR expression values obtained for each gene differ between them in most of the genes by less than 30\% (see Experimental Procedures for a more detailed explanation). The values for some of these genes have been published previously and are depicted for comparative purposes.

RpoS regulated reported genes [Weber et al., 2005, Byocyc http://www.ecocyc.org/] are shown with +/signs. Genes marked with an asterisk are genes reported in this work as regulated by RpoS. and PB12 (table 2). These values indicate the different relative roles of RpoS in these strains. In agreement with the previous results, the transcription of many genes was more RpoS-dependent in the absence of PTS. As shown in table 3 , the transcription levels of 18 genes (group 1) was downregulated in the $\mathrm{PTS}^{-} r p o S:: \mathrm{Tc}^{\mathrm{r}}$ strains, whilst they were unmodified in the wild-type $\mathrm{PTS}^{+} r p o S^{-}$derivative. The inactivation of $r p o S$ decreased the transcription levels of another group of 8 genes in both genetic backgrounds, $\mathrm{PTS}^{-}$and $\mathrm{PTS}^{+}$(table 3, group 2). Interestingly, inactivation of rpoS in JM101 resulted in the upregulation of a group of 5 genes that were downregulated in the PTS $^{-}$strains (table 3, group 3). Finally, the $s d h A B$ genes were upregulated in $\mathrm{PB} 12 \mathrm{rpoS}^{-}$and $\mathrm{PB} 11 \mathrm{rpoS}^{-}$as compared to their parental strains PB11 and PB12 (table 3, group 4). As mentioned these results give evidence of the differential roles of RpoS in the two strains and also confirm that the promoters of these genes share both, sigma 70 and sigma $S$ recognition sites.

A possible explanation for the diverse roles of RpoS in the transcription of various genes in the two genetic back-
Table 2. Specific growth rate determinations $\left(\mu=h^{-1}\right)$ for the JM101 parental strain, the PB11 and PB12 PTS $^{-}$derivatives and their rpos::Tc ${ }^{\mathrm{r}}$ derivatives

\begin{tabular}{lll}
\hline Strain & Glc & Glc-Ac \\
\hline JM101 & 0.71 & 0.68 \\
JM101 rpoS::Tc & 0.71 & 0.68 \\
PB11 & 0.12 & 0.26 \\
PB11 rpoS::Tc & 0.06 & 0.2 \\
PB12 & 0.42 & 0.48 \\
PB12 rpoS::Tc & 0.38 & 0.42
\end{tabular}

The specific growth rate determinations are the results of the averages of three independent growth experiments. The cells were grown on glucose or glucose plus acetate (Ac) as carbon sources.

grounds might be that in PTS$^{-}$backgrounds the cells sensed a permanent condition of glucose or glucose-6phosphate internal limitation which resulted in decreased growth rates and thereby increased levels of ppGpp. Un- 
Fig. 1. Transcription values of central metabolic genes in PB11 and PB11 rpoS::Tcr . Central metabolic routes showing key metabolites and the genes involved in their transformation. RT-PCR values are shown close to the gene in parentheses for PB11 rpoS::Tc ${ }^{\mathrm{r}}$ and underlined in parentheses for PB11; see table 1 for the complete set of RTPCR values. The abbreviations are: GLC = glucose; $\mathrm{G} 6 \mathrm{P}=$ glucose-6-phosphate; F6P = fructose- 6 -phosphate; F1,6P = fructose-1,6-phosphate; DHAP = dihydroxyacetone-phosphate; G3P = glyceraldehyde3-phosphate; G1,3P = glyceraldehyde-1,3phosphate; $3 \mathrm{PG}=3$-phosphoglycerate; $2 \mathrm{PG}=2$-phosphoglycerate; $\mathrm{PEP}=$ phosphoenolpyruvate; PYR = pyruvate; AC$\mathrm{CoA}=$ acetyl-CoA; Ac-P = acetyl phosphate; A-AMP = acetyl-AMP; CIT = citrate; ICT = isocitrate; Gox = glyoxylate; $\alpha-\mathrm{KG}=\alpha$-ketoglutarate; SUC-CoA $=$ succinyl-coenzyme A; SUC = succinate; $\mathrm{FUM}=$ fumarate; $\mathrm{MAL}=$ malate; $\mathrm{OAA}=$ oxaloacetate; $6 \mathrm{PGNL}=6$-phosphogluconolactone; $6 \mathrm{PGNT}=6$-phosphogluconate; RU5P = ribulose-5-phosphate; R5P = ribose-5-phosphate; X5P = xylulose-5-phosphate; S7P = sedoheptulose-7-phosphate; $\mathrm{E} 4 \mathrm{P}=$ erythrose-4-phosphate; KDPGNT = 2-keto-3-deoxy-6-phosphogluconate; DAHP = 3-deoxy-D-arabino-heptulosonate-7-phosphate; $\mathrm{mez}=$ malic enzymes.

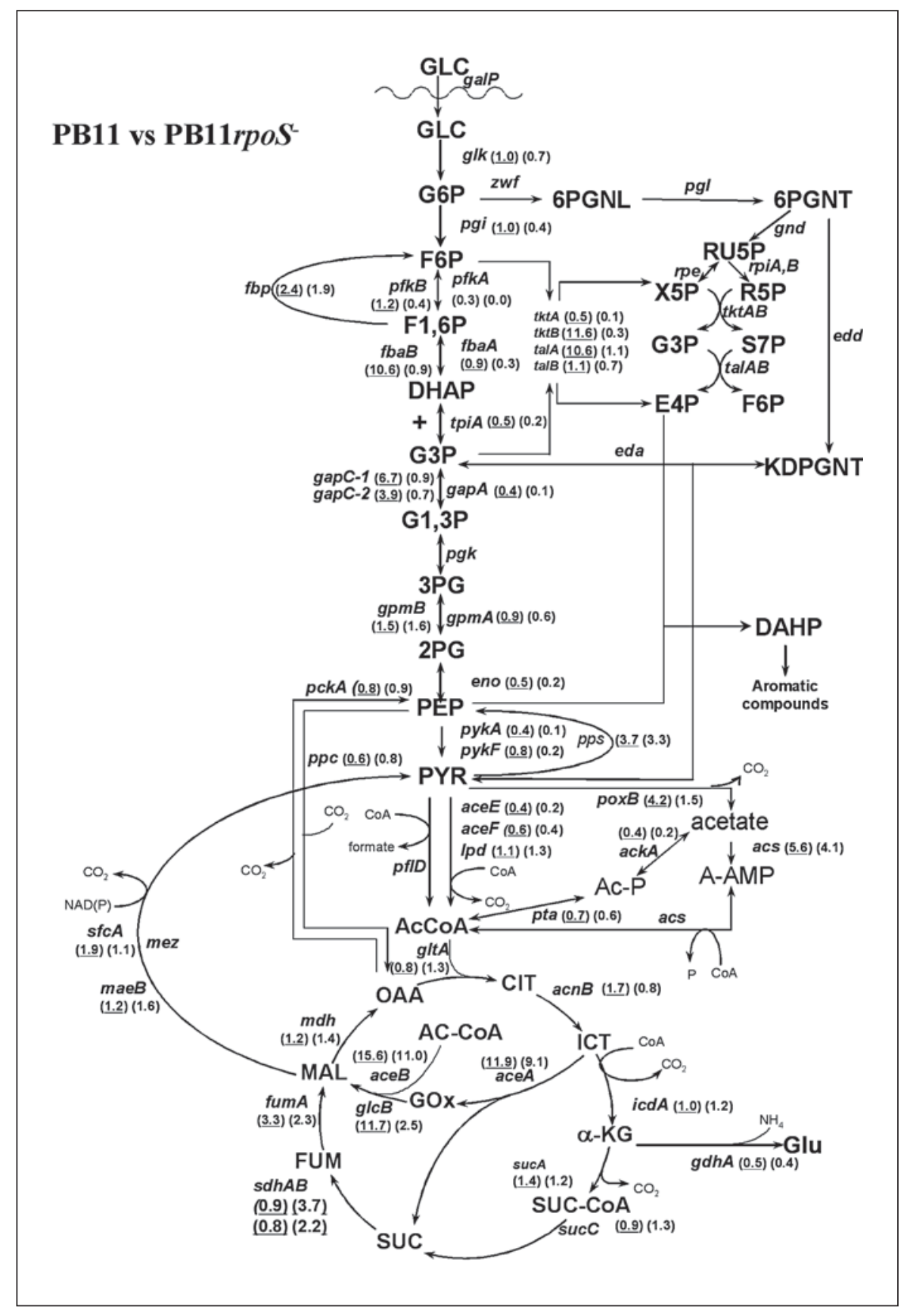

der these circumstances, the genes commonly transcribed by sigma 70 in non-stress conditions (genes in group 1) were preferentially transcribed by RpoS. The transcription of the second group of genes was highly RpoS-dependent in both $\mathrm{PTS}^{-}$and $\mathrm{PTS}^{+}$strains, since the inactivation of $r p o S$ clearly decreased their transcription. In the third group, there was apparently an opposite role of RpoS in the different backgrounds. For these genes, RpoS had a repressor-like role in the $\mathrm{PTS}^{+}$background, while it apparently had an activator role in the PTS $^{-}$strains. Finally, in the case of $s d h A B$ genes, the inactivation of RpoS increased their transcription levels indicating a possible repressor role for RpoS. It is interesting that repressor-like roles for RpoS have been reported in an $E$. coli B rpos- derivative growing logarithmically for the TCA, aceEF and $l p d$ genes [Rahman et al., 2006]. 
Fig. 2. Transcription values of central metabolic genes in PB12 and $\mathrm{PB} 12$ rpoS::Tc ${ }^{\mathrm{r}}$ strains. This figure and table 1 present the relative transcription values of central metabolic genes in $\mathrm{PB} 12$ and $\mathrm{PB} 12$ rpoS:: $\mathrm{Tc}^{\mathrm{r}}$ strains. RT-PCR values are shown close to the gene in parentheses for PB12 rpoS:: $\mathrm{Tc}^{\mathrm{r}}$ and underlined in parentheses for PB12. See table 1 for the complete set of RT-PCR values. Symbols as in the legend to figure 1.

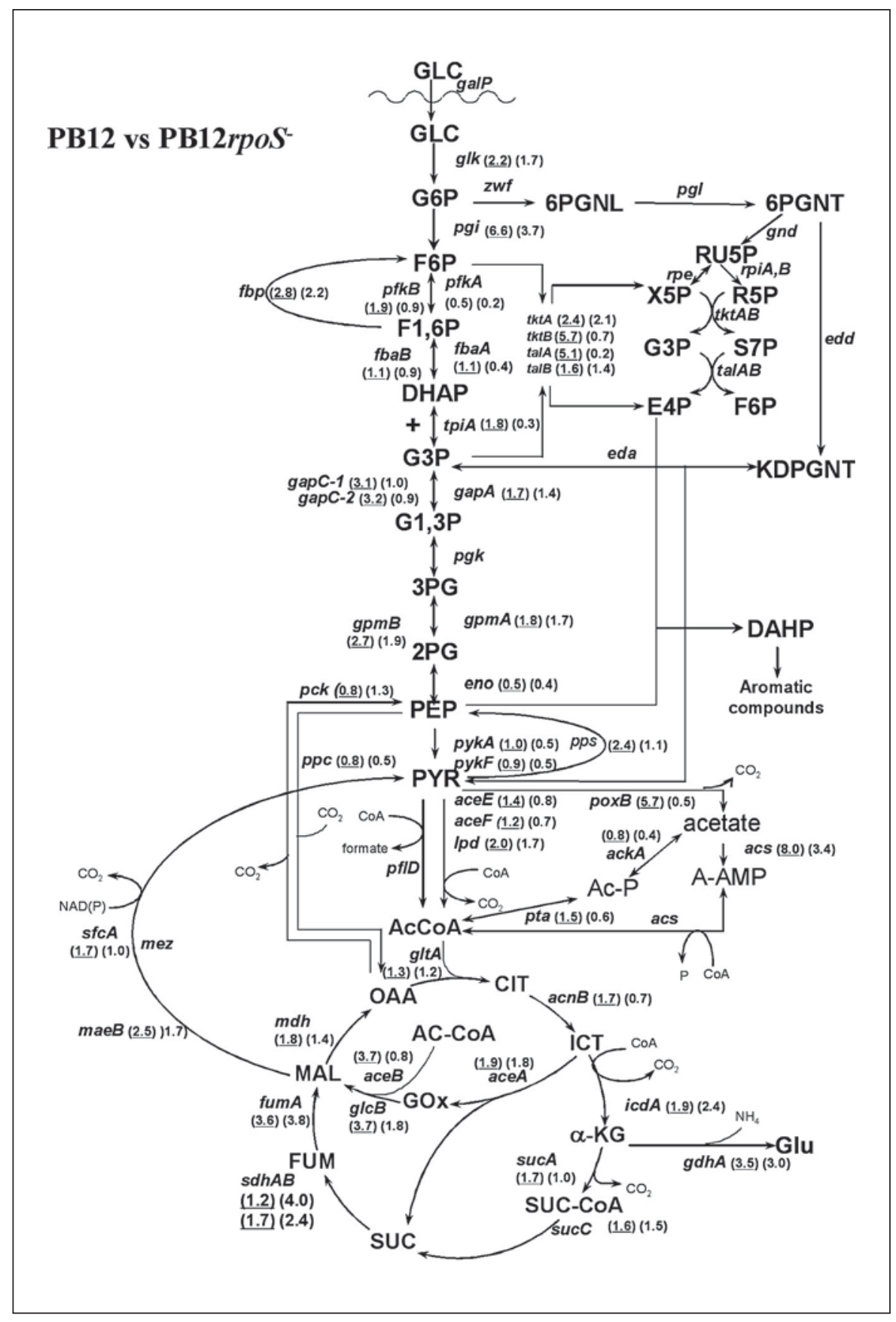

Transcription and Regulation of the Genes Involved in the Synthesis of $p p p G p p$ and $p p G p p$

As has been mentioned, many E. coli genes, whose transcription is controlled by alternative sigma factors such as RpoS, are poorly induced in cells lacking the alarmone ppGpp because this metabolite is required to increase the RpoS-binding capacity to the RNA polymerase core. It is known that RelA and SpoT are involved in the synthesis of pppGpp and that the enzyme Gpp transforms this metabolite into ppGpp. Furthermore, SpoT is also involved in the degradation of this alarmone into GDP and PPi, and Ppa transforms PPi into Pi. Finally, Ndk converts GDP into GTP, while SpoT utilizes this metabolite to produce pppGpp [Lengeler et al., 1999, fig. 3]. It is remarkable that the transcription levels of $s p o T, g p p$, $p p a$ and $n d k$ that encode these related enzymes were 3 - to 
Table 3. Transcription dependency on RpoS

\begin{tabular}{|c|c|c|c|}
\hline Gene & JM101 rpos- & PB11 rpos- & PB12 rpos \\
\hline \multicolumn{4}{|c|}{$\begin{array}{l}\text { Group 1: Genes displaying transcription downregulation by rpoS } \\
\text { inactivation only on } \text { PTS }^{-} \text {strains }\end{array}$} \\
\hline aceBA & $=$ & $\nabla$ & $\nabla$ \\
\hline $\operatorname{ack} A$ & $=$ & $\nabla$ & $\nabla$ \\
\hline$a c n B$ & $=$ & $\nabla$ & $\nabla$ \\
\hline acs & $=$ & $\nabla$ & $\nabla$ \\
\hline $\operatorname{adhP}$ & $=$ & $\nabla$ & $\nabla$ \\
\hline $\operatorname{arc} A$ & $=$ & $\nabla$ & $\nabla$ \\
\hline eno & $=$ & $\nabla$ & $\nabla$ \\
\hline$f b a B$ & $=$ & $\nabla$ & $\nabla$ \\
\hline $\operatorname{gad} A$ & $=$ & $\nabla$ & $\nabla$ \\
\hline galE & $=$ & $\nabla$ & $\nabla$ \\
\hline katE & $=$ & $\nabla$ & $\nabla$ \\
\hline malP & $=$ & $\nabla$ & $\nabla$ \\
\hline$p f k B$ & $=$ & $\nabla$ & $\nabla$ \\
\hline pgi & $=$ & $\nabla$ & $\nabla$ \\
\hline poxB & $=$ & $\nabla$ & $\nabla$ \\
\hline pykA & $=$ & $\nabla$ & $\nabla$ \\
\hline pykF & $=$ & $\nabla$ & $\nabla$ \\
\hline spot & $=$ & $\nabla$ & $\nabla$ \\
\hline
\end{tabular}

Group 2: Genes displaying transcription downregulation by rpoS inactivation on $\mathrm{PTS}^{-}$strains and wild-type derivatives

\begin{tabular}{|c|c|c|c|}
\hline$f b a A$ & $\nabla$ & $\nabla$ & $\nabla$ \\
\hline$g p p$ & $\nabla$ & $\nabla$ & $\nabla$ \\
\hline osm $Y$ & $\nabla$ & $\nabla$ & $\nabla$ \\
\hline$p f k A$ & $\nabla$ & $\nabla$ & $\nabla$ \\
\hline$p p a$ & $\nabla$ & $\nabla$ & $\nabla$ \\
\hline rpos & $\nabla$ & $\nabla$ & $\nabla$ \\
\hline talA & $\nabla$ & $\nabla$ & $\nabla$ \\
\hline$t k t B$ & $\nabla$ & $\nabla$ & $\nabla$ \\
\hline tpiA & $\nabla$ & $\nabla$ & $\nabla$ \\
\hline
\end{tabular}

Group 3: Genes displaying an opposite transcription effect of $r p o S$ inactivation. Upregulation in JM101 and downregulation in PTS derivatives

\begin{tabular}{|c|c|c|}
\hline aceEF & $\Delta$ & $\nabla$ \\
\hline $\operatorname{ack} A$ & $\Delta$ & $\nabla$ \\
\hline $\operatorname{acn} A$ & $\boldsymbol{\Delta}$ & $\nabla$ \\
\hline gapC-1 & $\boldsymbol{\Delta}$ & $\nabla$ \\
\hline gapC-2 & $\Delta$ & $\nabla$ \\
\hline$s f_{c} A$ & $\bar{\Delta}$ & $\nabla$ \\
\hline
\end{tabular}

Group 4: Genes displaying upregulation by rpoS inactivation in PTS $^{-}$mutants

$\begin{array}{llll}s d h A & = & \Delta & \Delta \\ s d h B & = & \Delta & \Delta\end{array}$

Indicates that the transcription level is downregulated; = indicates no significant change in the transcription level, and $\boldsymbol{\Delta}$ indicates transcription upregulation. 5-fold upregulated in both PB12 and PB13, as compared to PB11 and JM101 (fig. 3; table 1). Interestingly, the transcription level of the relA gene was not significantly modified. These results are in agreement with the proposition that during carbon starvation an alternative RelA-independent pathway for the synthesis of ppGpp is activated [Lengeler et al., 1999]. The upregulation of all these genes located in different transcription units at different positions of the E. coli chromosome [Gentry et al., 1993; GenBank accession number NC000913], could be the result of a mutation inactivating a common regulatory molecule which in turn allowed a higher transcription of these genes. A higher transcription level of spoT and $g p p$ could in turn modify the levels of SpoT and Gpp. The high level transcription of RpoS-dependent genes in $\mathrm{PTS}^{-}$strains could be important not only for maintaining the transcription of certain genes under nutrient-limited growth conditions, but also for the selection of strains capable of reaching a higher $\mu$ on glucose as is the case for PB12 and $\mathrm{PB} 13$. In agreement with this proposition, rpoS inactivation in $\mathrm{PB} 11$ rpoS:: $\mathrm{Tc}^{\mathrm{r}}$ strain clearly decreased its specific growth rate by $50 \%$ as compared to PB11, while the PB12 rpoS::Tc ${ }^{\mathrm{r}}$ strain decreased its $\mu$ by only $10 \%$ as compared to $\mathrm{PB} 12$. On the contrary, the $\mu$ of the wild-type strain was not affected by the presence of the $r p o S:: \mathrm{Tc}^{\mathrm{r}}$ mutation (table 2). These results are also in accordance with the 3and 2-fold transcription upregulation of the rpoS gene in PB11 and PB12, respectively, indicating that under these non-optimal nutrient-limited growing conditions, the role of RpoS was important in both $\mathrm{PTS}^{-}$strains, although in PB11 it was more relevant.

There are different explanations for the isolation and preservation of a mutation upregulating the $s p o T$ and $g p p$ genes. In a first scenario, the mutation that caused upregulation of these genes could be responsible for generating higher levels of ppGpp in PB12 or in a precursor strain. This mutation could have been selected and maintained because it allowed the transcription of RpoS-dependent genes in this $\mathrm{PTS}^{-}$strain, in which the level of RpoS could be lower because the $r p o S^{-}$point mutation was not completely suppressed. Alternatively, the mutation upregulating spoT and $g p p$ could have been selected to increase the transcription of RpoS-dependent genes in the PB11 background and this in turn could have increased the $\mu$ of this strain. In this second scenario, the rpoS point mutation was later selected in PB12 or a precursor strain and this could have diminished the levels of $r p o S$ transcription because this mutation was not completely suppressed. In a third scenario, the upregulation of spoT and $g p p$ could have decreased the levels of ppGpp in PB12 as compared 


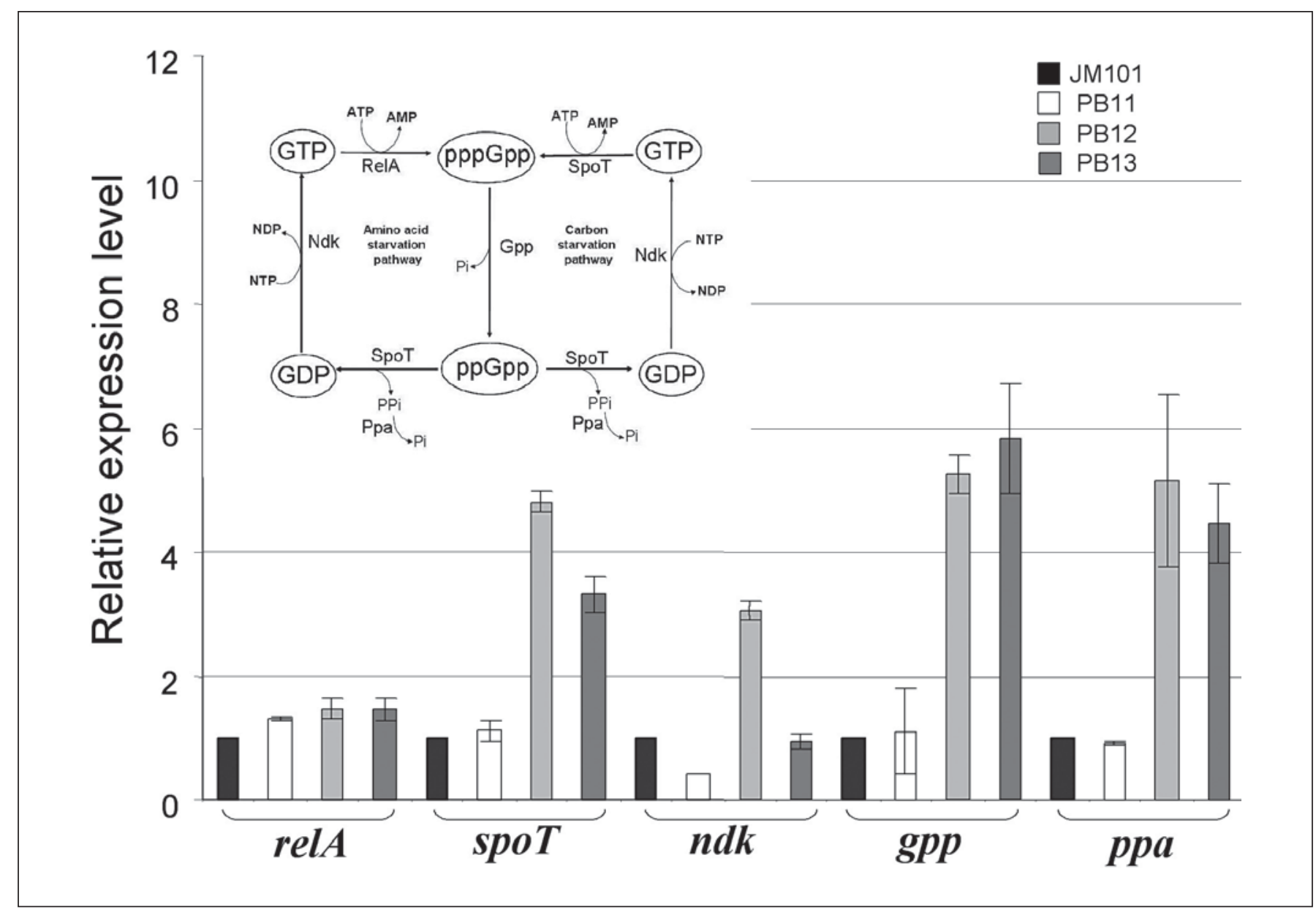

Fig. 3. Relative transcription expression values of genes involved in ppGpp metabolism. This figure and table 1 present the comparative expression of genes whose products are involved in ppGpp metabolism. The transcription values of relA, gpp, spoT, $p p a$ and $n d k$ are presented. The figure also shows, in the left upper part, the role of the enzymes coded by these genes in ppGpp metabolism.

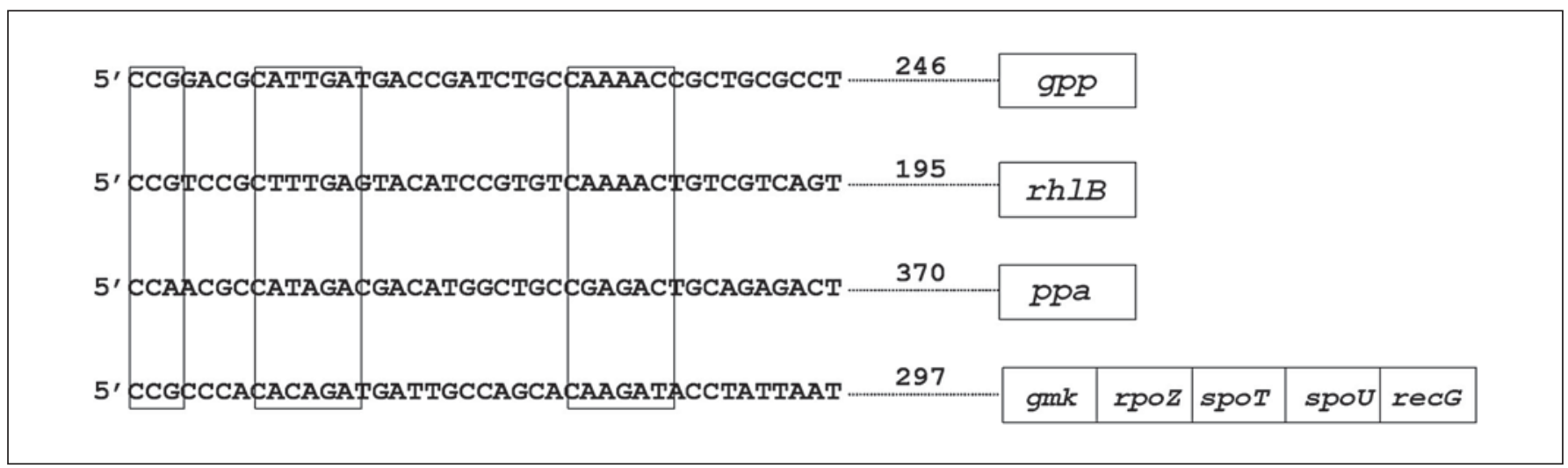

Fig. 4. Nucleotide sequences of the putative 41-bp regulatory boxes located at the $5^{\prime}$ upstream regions of the $g p p$, $p p a, r h l B$ and $g m k-s p o T$ transcription units. The numbers indicate the distances in base pairs to the ATG start codons of the depicted genes. 
to PB11, in order to reduce the transcription role of RpoS in PB12, or in a precursor strain. In this scenario, the appearance of the rpoS point mutation could have lowered the amount of active RpoS even further. This last scenario is in agreement with the fact that PB12 may sense less nutritional stress conditions than PB11, a condition in which less ppGpp is expected to be present. This fact could have given PB12 an altered transcription capability where sigma 70 could play a more important role but still maintains RpoS transcription of some important genes, allowing this strain a faster growth on glucose than PB11. However, since PB12 did not arise directly from PB11 and at least two mutations that appeared in an unknown order gave rise to PB12, it was difficult to propose a simple hypothesis to explain how the levels of ppGpp were modified and selected giving rise to PB12 which certainly grows faster than PB11 but still is RpoS-dependent to some extent. In any case, a mutation involved in ppGpp metabolism was selected that allowed the upregulation of spoT and $g P p$ genes in PB12 or in a precursor strain.

We cannot rule out that this mutation was also responsible for the upregulation of other genes in PB12 (such as glk and pgi). However, it is interesting to point out that three of these four genes $s p o T$, $g p p$, and $p p a$ share a 41-bp DNA box located at the $5^{\prime}$ terminus region outside their transcriptional units (fig. 4) that apparently is not present in any other region in the bacterial chromosome, except for the $r h l B$ gene whose expression was also upregulated (table 1). This box, if functional, could play a role in the recognition of a regulatory protein involved in the transcriptional upregulation of these genes. Preliminary evidence shown in figure 5 indicates that this box could play a role in the expression of these genes. A 586-bp DNA fragment, carrying the wild-type $5^{\prime}$ region including the 41-bp box and the first 20 nucleotides of the gmk-spoT operon, was cloned in front of a reporter lac $Z$ gene. When this DNA fragment was integrated into the chromosome of the wild-type JM101 and PB11 strains, white colonies were obtained when the cells were plated in the reported medium (see Experimental Procedures). On the other hand, when the same fragment was integrated into the PB12 chromosome, blue colonies were obtained (appear as dark colonies in fig. 5). These results indicate that the proposed regulatory protein thought to be inactive in $\mathrm{PB} 12$, and therefore allowing the upregulation of $g m k$ spoT and other genes in this strain, was active in JM101 and PB11 and did not allow the upregulation of either gmk-spoT (as indicated by the RT-PCR results) or the reporter gmk-lacZ fusion in these two parental strains. A second DNA fragment, carrying only the first $297 \mathrm{bp}$ from the $5^{\prime}$ region including $20 \mathrm{bp}$ of the gmk structural gene, was also used to construct a different gmk-lacZ fusion. This new construction did not include the putative 41-bp box, or the additional $248 \mathrm{bp}$ upstream from the putative regulatory DNA region (fig. 5). When this new construction was integrated into the chromosome of JM101, PB11 and PB12, all derivative strains gave rise to blue colonies. These results indicate that the 289-bp DNA region including the identified regulatory 41-bp box, modulated the transcription of the gmk-spoT operon. A possible explanation might be that a putative protein could bind to this DNA region with a regulatory effect on the downstream genes. When this DNA region, which carried the reporter gmk-lac $Z$ fusion gene, was absent in JM101 and PB11 derivative strains, the putative regulatory protein was unable to bind to DNA and this enabled the transcription upregulation of these genes as indicated by the appearance of blue colonies of these derivative strains. As expected, in the case of PB12, both types of DNA fragments gave rise to blue colonies due to the absence of the putative regulatory protein that should be inactive in PB12, permitting the upregulation of $g m k$-spoT and perhaps $p p a$ and $g p p$. As expected in all the blue colonies, $\beta$ galactosidase activity was detected (between 2000 and 4000 units) while in the white colonies no activity was found (data not shown). These experiments, while not conclusive, indicate a possible role of this 41-bp putative DNA box in the regulation of these genes. Although this putative regulatory site is located far upstream from its corresponding regulatory target, it is known that in $E$. coli long-range interactions of DNA regions are feasible by the formation of DNA-looping repressor structures by specific proteins and nucleoprotein complexes that may include $\mathrm{H}-\mathrm{Ns}$ or Fis. The formation of this kind of DNA structure can block the access of the RNA polymerase to the promoter region and thus regulate gene expression [for review, see Semsey et al., 2005; Fried and Hudson, 1996].

Finally, It is important to note that the inactivation of rpos in both strains PB11 rpoS::Tc ${ }^{\mathrm{r}}$ and $\mathrm{PB} 12$ rpos:: $\mathrm{Tc}^{\mathrm{r}}$ clearly decreased the transcription level of $g p p$ and reduced in half the transcription levels of spoT and $p p a$, indicating that the transcription of the first gene was highly dependent whereas spoT and $p p a$ transcriptions were at least partially dependent on RpoS. On the other hand, the transcription of $n d k$ and $r e l A$ was not affected by the rpoS mutation in the $\mathrm{PTS}^{-}$strains. Interestingly, the transcription level of $g p p$ was also clearly reduced in JM101 rpoS::Tc $\mathrm{Tc}^{\mathrm{r}}$, while the transcription levels of $s p o T$ as well as $n d k$ and $r e l A$ were not affected in this $\mathrm{PTS}^{+}$strain (fig. 3; table 1). 


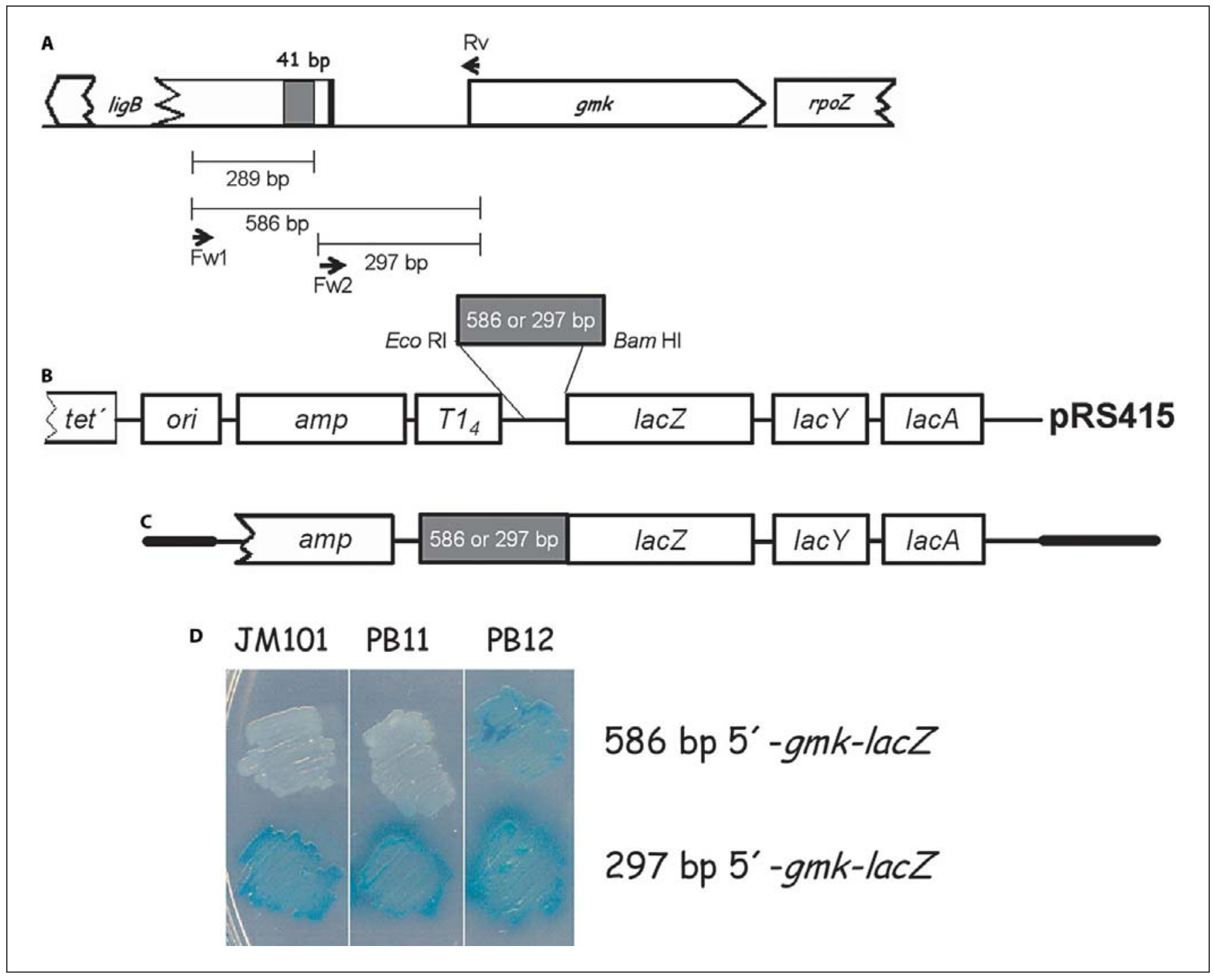

Fig. 5. Construction of the gmk-lacZ transcriptional chromosomal fusions. For the construction of the chromosomal translation $g m k$-lacZ fusions two DNA regions were employed. The first corresponded to the first $586 \mathrm{bp}$ upstream of the $g m k$ structural gene. This fragment included: the 297-bp ligB-gmk intergenic region containing the first $20 \mathrm{bp}$ of the gmk structural gene, and part of the $\operatorname{lig} B$ gene where the 41-bp putative box is located. The second DNA fragment used in the gmk-lacZ translation fusion only included the 297-bp DNA intergenic fragment carrying the first 20 bp of the gmk structural gene (A). These amplified DNA frag- ments were cloned into plasmid pRS415, including the $\beta$-lactamase gene $(b l a)$ with the $\mathrm{T}_{4}$ terminator, allowing the construction of the two different $g m k$-lacZ fusions (B). These fusions were transferred into phage $\lambda$ RS45 (C). Phage derivatives containing the two different $g m k$-lac $Z$ fusions were utilized for the infection of strains JM101, PB11 and PB12. Blue and white phenotypes (that appear as dark and pale grays) were screened for the different derivative strains carrying the 586- and 297-bp gmk-lac $Z$ fusions (D). For a more detailed explanation see the Experimental Procedures and Discussion sections in the text.

\section{Growing Capacities of the PTS- Strains and Their rpoS $^{-}$Derivatives}

As has been mentioned, the $\mu$ on glucose of the rpos: $\mathrm{Tc}^{\mathrm{r}}$ derivatives of strains PB11 and PB12 was decreased by 50 and $10 \%$, respectively, as compared to the parental strains, while the $\mu$ of the JM101 rpoS::Tc ${ }^{\mathrm{r}}$ derivative was not affected when compared to the wild-type strain (table 2). These results indicate the different and important roles of RpoS in the PTS ${ }^{-}$strains, when growing in this carbohydrate as the unique carbon source. Interestingly, the gluconeogenic capacities of PB11 when growing on glucose are still present in the $\mathrm{PB} 11$ rpoS:: $\mathrm{Tc}^{\mathrm{r}}$ derivative 
strain. The transcription of the glyoxalate shunt genes ace $B A$ and $g l c B$, as well as acs involved in acetate conversion into $\mathrm{AcCoA}$ is still upregulated, although not as highly as in PB11 (fig. 1; table 1). These results explain why this strain is still capable of growing more than $100 \%$ faster on glucose complemented with acetate as compared to the growth with only glucose as the sole carbon source given its capacity of co-utilizing both carbon sources as occurred with the parental strain PB11 (table 2). In the case of the PB12 rpoS::Tcr ${ }^{\mathrm{r}}$, the transcription of aceBA and $g l c B$ involved in the glyoxalate shunt was clearly diminished to the levels of the wild-type strain, while the transcription of acs was still 3-fold upregulated. When glucose and acetate are both present as carbon sources this strain increased its $\mu$ about $10 \%$ in a similar level to that of PB12 which increased its $\mu$ from 0.42 to 0.48 (table 2) [Flores $\mathrm{N}$ et al., 2005; Flores S et al., 2005].

\section{Concluding Remarks}

The role of the RpoS sigma factor has recently been reevaluated. Weber et al. [2005] demonstrated that RpoS is involved in the transcription of more than $10 \%$ of $E$. coli K-12 genes, and Rahman et al. [2006] have shown that in E. coli B this sigma factor plays an important role in the transcription of many genes of its central metabolic pathway, not only in carbon starvation conditions but also in logarithmic growing cultures. These results indicate that several central carbon metabolism genes are both RpoS- and RpoD-dependent.

We studied the effect of $r p o S$ inactivation in the JM101 strain and its PTS $^{-}$derivatives. When wild-type strain JM101 was grown logarithmically on glucose, the inactivation of rpoS did not substantially modify the transcription of most of the carbon central metabolism genes. These results indicate that most of the genes in $\mathrm{PTS}^{+}$ strains, growing logarithmically in minimal medium on glucose, are mainly sigma 70-dependent, as expected.

However, in the case of PTS- derivatives of JM101, which grow permanently under non-optimal nutrient conditions on glucose, there is an important RpoS dependency in the transcription of many genes. The specific growth rate of the $\mathrm{PB} 11$ rpoS::Tc ${ }^{\mathrm{r}}$ strain decreased $50 \%$ as compared to PB11 by the inactivation of $r p o S$, showing that important genes involved in these growing conditions are at least partially RpoS-dependent. This conclusion is supported by the fact that the transcription levels of many genes are downregulated in PB11 rpoS::Tc ${ }^{\mathrm{r}}$ as compared to the parental PB11 strain, including most glycolytic genes. 19 of these genes have not been previously reported as part of this modulon in E. coli K12 [Weber et al., 2005]. These results clearly demonstrate the important role of RpoS in this PTS- E. coli strain.

During the adaptive evolution fermentation process for the selection of PB12 and PB13 from PB11, as strains capable of faster growth on glucose, several mutations occurred that favored this purpose [Flores $\mathrm{N}$ et al., 1996]. In this report we identified one of these changes, corresponding to a point mutation that generated a stop codon in the rpoS gene in both PB12 and PB13 strains. However, since these strains carry the supE gene that suppresses stop codon amber mutations, the rpoS point mutation should be at least partially suppressed in PB12. In accordance with this proposition, the transcription of highly RpoS-dependent genes in PB12 is still upregulated but not as high as PB11. A possible selective force behind the appearance of this type of mutation at the rpoS gene could be the appearance of a strain with less RpoS activity in which the point mutation was not completely suppressed. Less RpoS protein could in turn allow this strain a faster growth on glucose because certain RpoS-dependent genes could then be transcribed by RpoD. Interestingly, in strains PB12 and PB13, but not in the parental JM101 and PB11, the transcription levels of several genes such as $g p p, s p o T$, $p p a$ and $n d k$ related to ppGpp metabolism are increased 3- to 5-fold. It is possible that the enhanced transcription rate of this group of genes was selected, in $\mathrm{PB} 12$ or in a precursor strain during the adaptive evolution fermentation experiment, to allow a faster growth on glucose by modifying, probably decreasing, the ppGpp concentration. This should allow a strain already carrying a $r p o S^{-}$point mutation, which could be only partially suppressed, an even more important role than RpoD over RpoS in the transcription of key genes, reflecting in this manner less stressed conditions but at the same time permitting the partial transcription by RpoS of certain genes required for the selection and/or the maintenance of a faster growth in a still non-optimal nutrient condition. Among these genes, a likely candidate could be $p g i$ whose transcription is upregulated 6-fold in PB12 as compared to PB11. When rpoS was inactivated in PB12, generating strain $\mathrm{PB} 12$ rpoS:: $\mathrm{Tc}^{\mathrm{r}}$, the transcription levels of several genes, known to be transcribed by RpoS were decreased as was the case of pgi. Therefore, it is clear that the translation of the rpoS mRNA in PB12 produced enough functional RpoS to transcribe certain genes. However, the in-

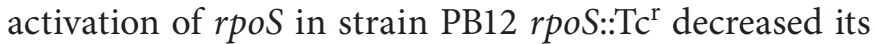
growth rate by only $10 \%$ as compared to PB12. These results indicate that PB12 still senses non-optimal nutrient 
growing conditions, although to a less significant degree than PB11 when glucose is utilized as the only carbon source. Consequently, the level of ppGpp in PB12 should be lower than in PB11. Nevertheless, the upregulation of many RpoS-dependent genes would not be possible without the presence of enough ppGpp to enable the utilization of RpoS for their transcription.

Interestingly, the transcription of $g p p$, spoT and $p p a$ was also dependent on RpoS, since their expressions clearly diminished in strains $\mathrm{PB} 11$ rpoS:: $\mathrm{Tc}^{\mathrm{r}}$ and $\mathrm{PB} 12$ rpoS::Tcr. On the other hand, the transcription of relA and $n d k$ was found to be independent of RpoS. These data provide clear evidence, not previously reported, for the different roles of RpoS in these two mechanisms that are involved in the synthesis of ppGpp. One of the mechanisms is related to RelA through the stringent response and the other through carbon starvation where the transcription of spoT and $g p p$ is dependent on RpoS, at least under non-optimal carbon-limited growth conditions in these PTS $^{-}$strains. Our results are in agreement with and extend those reported by Weber et al. [2005], where $10 \%$ of the genes of the bacterial genome in the $\mathrm{PTS}^{+}$wild-type strain were reported to be under RpoS control in different non-optimal growth conditions. Apparently, in the PTS ${ }^{-}$ strains non-optimal growing conditions are permanent when growing on glucose, especially in PB11. As mentioned, the inactivation of $r p o S$ in these $\mathrm{PTS}^{-}$strains allowed the identification of an additional group of 19 genes, not previously reported whose transcription is at least partially controlled directly or indirectly by RpoS.

Finally, the isolation of a mutation that simultaneously upregulated the transcription of the $s p o T, g p p, p p a$ and $n d k$ genes, required in the synthesis and degradation of ppGpp, could not be directly obtained from the parental $\mathrm{JM} 01 \mathrm{PTS}^{+}$strain as wild-type strains have several redundant mechanisms to deal with carbon utilization in logarithmic and starvation conditions. The isolation of this mutation became feasible in a $\mathrm{PTS}^{-}$strain (PB12), permanently growing under carbon-limited non-optimal conditions on glucose, most probably because this situation changed the levels of ppGpp allowing a transcription modification specificity of many genes permitting a more relevant role for $\mathrm{RpoD}$, although still maintaining transcription by RpoS of important genes in this strain. This is a clear example of the importance of the utilization and characterization of strains with mutations in general regulators, such as PTS and RpoS, for the purpose of identifying and characterizing other important regulatory elements in the network, such as the one described here, which is involved in the regulation of the expression of genes responsible for the synthesis and degradation of the alarmone ppGpp that is required for sigma S functionality. We cannot rule out that the upregulation of other genes in PB12 (such as glk and pgi) could depend on the same regulatory element responsible for the upregulation of $s p o T, g p p$ and $p p a$. However, it is interesting that these three genes share a putative DNA box sequence present in E. coli only at the $5^{\prime}$ upstream regions of these genes localized at different chromosomal positions with only one exception, the rhlB gene, which encodes a putative ATP-dependent RNA helicase. In this report, preliminary data are presented in favor of a possible role of this DNA box in the expression of these genes. So far, a possible regulatory protein involved in the expression of this group of genes has not been reported. Attempts will be made towards its isolation, characterization and to understand in more detail its possible role in the genetic network under different metabolic conditions.

\section{Experimental Procedures}

Bacterial Strains, Construction of $r p o S^{-}$Derivatives, Media and Growth Conditions

E. coli strains PB12 and PB13 (JM101 $\Delta$ (ptsH, ptsI, crr)::kan, $\mathrm{Glc}^{+}$) were obtained from PB11 (JM101 $\Delta(p t s H$, ptsI, crr)::kan), a PTS $^{-}$mutant derivative of E. coli JM101 ( $\mathrm{F}^{\prime}$ traD36 pro $A^{+}$pro $B^{+}$ lac $^{\mathrm{q}} \Delta$ (lacZ)Z15/supE thi $\Delta($ lac-proAB)) [Bolívar et al., 1977; Flores N, 1995]. rpoS ${ }^{-}$derivatives of these strains were obtained by P1 transduction using strain RH90 rpoS:: $\mathrm{Tc}^{\mathrm{r}}$ as donor of $r p o S:$ : $\mathrm{Tc}^{\mathrm{r}}$. Duplicate cultures for RNA isolation, acetate and glucose measurements by HPLC and specific growth rate $(\mu)$ determinations were grown on 1 liter fermentors on M9 medium with $2 \mathrm{~g} / \mathrm{l}$ of glucose or $2 \mathrm{~g} / \mathrm{l}$ of glucose plus $12 \mathrm{mM}$ of acetate, at $37^{\circ} \mathrm{C}, 600$ rpm controlling $\mathrm{pH}$ at 7 with $\mathrm{NaOH}$ and air flow rate of $1 \mathrm{vvm}$. Bacterial growth monitoring started at an $\mathrm{OD}_{600}$ of 0.05 and cells were collected when growing in the log phase at an $\mathrm{OD}_{600}$ of 1. E. coli strain DH5 $\alpha$ [Simons et al., 1987] was used for the construction of gmk-lacZ fusions.

\section{RNA Extraction and cDNA Synthesis}

Total RNA extraction was performed using hot phenol equilibrated with water. After extractions, RNA was precipitated with $3 \mathrm{M}$ sodium acetate/ethanol and centrifuged $20,000 \mathrm{~g}$ at $4^{\circ} \mathrm{C}$. Supernatant was discarded and the RNA resuspended in water. RNA was treated with DNase kit (DNA-free ${ }^{\mathrm{TM}}$, Ambion) and its concentration measured by densitometry in agarose gels and by 260/280 nm ratio absorbance. cDNA was synthesized using RevertAid $^{\mathrm{TM}} \mathrm{H}$ First Strand cDNA Synthesis kit (Fermentas Inc.) and a mixture of specific DNA primers. The list with the sequences of the primers of some of the specific genes utilized in this work has been published in Flores $\mathrm{N}$ et al. [2005]. The non-published sequences are listed in table 4. cDNA was used as template for RTPCR assays. Reproducibility of this procedure was determined by 
performing two separate cDNA synthesis experiments from the RNA extracted for each strain. Similar results were obtained for the transcription of all measured genes.

\section{Real-Time PCR}

RT-PCR was performed with the ABI Prism 7000 Sequence Detection System (Perkin-Elmer/Applied Biosystems) using the SYBR Green PCR Master Mix (Perkin-Elmer/Applied Biosystems). Amplification conditions were $10 \mathrm{~min}$ at $95^{\circ} \mathrm{C}$, and a twostep cycle at $95^{\circ} \mathrm{C}$ for $15 \mathrm{~s}$ and $60^{\circ} \mathrm{C}$ for $60 \mathrm{~s}$ for a total of 40 cycles. Primers for specific amplification were designed using the Primer Express software (PE/Applied Biosystems) and have been published [Flores $\mathrm{N}$ et al., 2005]. The only primers not published are shown in table 4 . The size of all amplimers was $101 \mathrm{bp}$. The final primer concentration, in a total volume of $15 \mu \mathrm{l}$ was $0.2 \mu \mathrm{M}$. Five nanograms of target cDNA for each gene utilized in this work was added to the reaction mixture. All experiments were performed in triplicate for each gene of each strain, obtaining very similar values (differences of less than $0.3 \mathrm{SD}$ ). A non-template control reaction mixture was included for each gene. The quantification technique used to analyze data was the $2^{-\Delta \Delta C T}$ method described by Livak and Shmittgen [2001], and the results were plotted.

Data were normalized using the ihfB gene as an internal control (housekeeping gene). The same expression level of this gene was detected in all the strains in the conditions tested. For each analyzed gene, the transcription level of the wild-type gene was considered as one and was used as the control to normalize the data. Therefore, data are reported as relative expression levels, compared to the expression level of JM101. The results presented in table 1 and in figures 1-3 are the averages of four independent measurements of the RT-PCR expression values for each gene. Half of the values were obtained from two different cDNAs generated from one fermentation procedure and the other two from another identical fermentation. RT-PCR expression values obtained for each gene differ by less than $30 \%$.

\section{Construction of gmk-lacZ Chromosomal Fusions}

Chromosomal gmk regulatory region-lacZ fusions were constructed as described by Simons et al. [1987]. Briefly, a chromosomal region of $586 \mathrm{bp}$ (including $289 \mathrm{bp}$, the possible regulatory 41-bp box, the intergenic ligB-gmk region and the first $20 \mathrm{bp}$ of the $5^{\prime}$-gmk structural gene) and a second chromosomal region of $297 \mathrm{bp}$ (including the intergenic ligB-gmk region excluding the possible regulatory 41-bp box, but including the first $20 \mathrm{bp}$ of the gmk structural gene) were amplified (fig. 4, 5). EcoRI restriction sites were incorporated in the two forward (Fw) primers (Fwl 5' CCCCGAATTCATTTTGCGTACACCCGTATGGG 3', Fw2 5'CCCCGAATTCATCGCCATCCATACTTTCATCATCAC3'), and a BamHI site was incorporated in the reverse $(\mathrm{Rv})$ primer $\left(5^{\prime}\right.$ CCCCGGATCCTAAAGCGTGCCTTGAGCCAT 3'; fig. 5). Each amplified product was digested and ligated into EcoRI/BamHI digested plasmid pRS415. Recombinant molecules were used to transform $E$. coli strain DH5 $\alpha$. Transformant cells were plated on LB with ampicillin $(200 \mu \mathrm{g} / \mathrm{ml})$. Alkaline minipreps of several colonies were performed and plasmids digested with EcoRI/ $B a m \mathrm{HI}$ to verify the size of the ligated chromosomal DNA region. The two different translational fusions of the gmk regulatory region and its first seven codons with the reporter lacZ (gmk-lacZ) fusions thus obtained were transferred to $\lambda$ RS45 phage using the following technique: $1-\mathrm{ml}$ aliquots of overnight culture LB sup-
Table 4. Nucleotide sequences of primers not previously published and used for RT-PCR assays

\begin{tabular}{|c|c|c|}
\hline Gene & Primer name & Primer sequence \\
\hline \multirow[t]{2}{*}{$\mathrm{kgm}$} & gmka & 5' ATCCAGCCTGATTCAGGCTTT 3' \\
\hline & gmkb & $5^{\prime}$ CGTGGACTTCACCAGGACG 3' \\
\hline \multirow[t]{2}{*}{$g P p$} & gppa & 5' AATTGCTGGCGACGCTACTG 3' \\
\hline & gppb & 5' GCAGAGTTGTTCTGCGAGCC 3' \\
\hline \multirow[t]{2}{*}{ katE } & katEa & $5^{\prime}$ CCAAAGCGGATTTCCTCTCA 3' \\
\hline & katEb & 5' ATCACGCACGGTATCAGCAG 3' \\
\hline \multirow[t]{2}{*}{ malP } & malPa & $5^{\prime}$ CTGGCGGCTCTGTTGGATAA 3' \\
\hline & malPb & 5' TGACGGAATTTCGCATCATC 3' \\
\hline \multirow[t]{2}{*}{ osm $Y$} & osmYa & 5' AAAGTTGAAACCACCGACGG 3' \\
\hline & osmYb & $5^{\prime}$ ACACCATCTACCGCTTTGGC $3^{\prime}$ \\
\hline \multirow[t]{2}{*}{$p p a$} & ppaa & 5' AATTGCTGGCGACGCTACTG 3' \\
\hline & ppab & $5^{\prime}$ GCAGAGTTGTTCTGCGAGCC $3^{\prime}$ \\
\hline \multirow[t]{2}{*}{ ptsG } & ptsGa & 5' AAAAGCGACAGGTACCAGCG 3' \\
\hline & ptsGb & 5' CGCGCAGACGGGTAATACAT 3' \\
\hline \multirow[t]{2}{*}{$\operatorname{rhlB}$} & rhlBa & 5' ATCAGCCGCGTGCCTTAAT 3' \\
\hline & rhlBb & $5^{\prime}$ ACCCAGCTTCAGGCCAGTAG 3' \\
\hline \multirow[t]{2}{*}{ rpoD } & rpoDa & 5' GATTCTGCGACCACCGAAAG 3' \\
\hline & $\mathrm{rpoDb}$ & 5' TCGATACCGAAACGCATACG 3' \\
\hline \multirow[t]{2}{*}{$\operatorname{spot}$} & spoTa & 5' ATCCGATCTCTTCCCGGATG 3' \\
\hline & spoTb & $5^{\prime}$ GCACTGCATAAGCGAAGTCG 3' \\
\hline
\end{tabular}

The sequences of primers of the remaining genes have been reported [Flores $\mathrm{N}$ et al., 2005].

plemented with $0.2 \%$ maltose and $10 \mathrm{mM} \mathrm{MgCl}_{2}$ of both $\mathrm{DH} 5 \alpha$ / pRS552 gmk-lacZ fusions were washed with buffer $\lambda(0.61 \mathrm{~g} / \mathrm{l}$ Trizma base $\mathrm{pH} 7.5,0.123 \mathrm{~g} / \mathrm{l} \mathrm{MgSO}_{4} \cdot 7 \mathrm{H}_{2} \mathrm{O}, 0.0278 \mathrm{~g} / \mathrm{l}$ anhydrous $\mathrm{CaCl}_{2}, 0.46 \mathrm{~g} / \mathrm{l} \mathrm{NaCl}$ ) and infected with $100 \mu \mathrm{l}$ of $\lambda \mathrm{RS} 45$ phage. $3 \mathrm{ml}$ of TAB soft agar were added to infected cells that were plated and incubated on at $37^{\circ} \mathrm{C}$. The $\lambda$ RS45 phage containing gmk-lac $Z$ fusions was harvested and a $10^{-3}$ dilution of phage suspension was used overnight to infect LB cultures of JM101, PB11 and PB12 strains grown in $\mathrm{TB}$ agar supplemented with maltose, $\mathrm{NaCl}$ and $\mathrm{MgCl}_{2}$. After infection, cells were washed and plated in TB agar supplemented with X-Gal and ampicillin $(200 \mu \mathrm{g} / \mathrm{ml})$. White or blue phenotypes were screened in LB with X-Gal for JM101, PB11 and $\mathrm{PB} 12$ derivative strains carrying 586- and 297-bp regulatory region $g m k$-lacZ fusions.

Chromosomal DNA was extracted from JM101, PB11, PB12 and derivative strains carrying the 586 and $297 \mathrm{gmk}$-lacZ fusions to verify the presence of the fusions by amplification using the adequate set of flanking primers. The size of the fragments obtained indicated the correct size of the amplified products for the different $g m k$-lacZ fusions. DNA sequencing of amplified products indicated the correct sequences of the amplified products (see below).

Nucleotide Sequence Determination and Analysis of rpoS and Other DNA Regions

$200 \mathrm{bp}$ located at the $5^{\prime}$ end and $100 \mathrm{bp}$ at the $3^{\prime}$ end of the rpoS structural gene and their coding regions were amplified by PCR using a set of primers designed with the Clone Manager Program. 
Chromosomal DNA (100 ng) from JM101, PB11, PB12 and PB13 strains was used as template for amplification. Also DNA from strains JM101, PB11 and PB12 carrying 586 and 297 bp gmk-lacZ fusions integrated at the chromosome was amplified by PCR with the Elongase enzyme mix, in accordance with the supplier's recommendations (Invitrogen, Inc.). PCR products were analyzed for expected size and purified using a PCR purification kit (Marligen, BioScience Inc.). Nucleotide sequences (data not shown) were determined from PCR templates by the Taq FS Dye Terminator Cycle Fluorescence-Based Sequencing method, with an Applied Biosystems Model 377-18 sequencer.

\section{Computer Analysis of Putative Regulatory Regions}

The $400 \mathrm{bp}$ upstream regions of the operons carrying the genes whose products are involved in ppGpp metabolism in $E$. coli (relA, $g p p$, spoT, $p p a$ and $n d k$ ), were used to search for significant over-represented sequence motifs; their comparative expressions are depicted in figure 4 . For this purpose, the public domain motif Multiple EM for the Motif Elicitation (MEME) program was utilized [Bailey and Elkan, 1994]. The common motif found by this analysis and its distance to the ATG start codon of the first gene of the operons is shown. The specificity of this motif was evaluated by search in all upstream regions of the E. coli genome using the MEME counterpart Motif Alignment and Search tool MAST [Bailey and Gribskov, 1998]. No new sequences were found in this search. The E. coli genome sequences used in the analysis were obtained from GenBank (AC number NC_000913).

\section{Acknowledgements}

We thank Paul Gaytán, Jorge Yáñez and Eugenio López for the synthesis of oligonucleotides (Instituto de Biotecnología, UNAM). We are grateful to Prof. Hengge-Aronis for the gift of the RH90 $\left(\right.$ rpoS::Tc $\left.{ }^{r}\right)$ strain. We also thank Mercedes Enzaldo, Roberto Encizo and Josué Villegas for technical support. This work was partially supported by CONACyT/México grants NC230, 43243, $37342-\mathrm{N}$ and DGAPA-PAPIIT-UNAM grants IN2204032, IN218902 and IN221106.

\section{References}

-Artsimovitch I, Patlan V, Sekine S, Vassylyeva MN, Hosaka T, Ochi K, Yokoyama S, Vassylyev DG: Structural basis for transcription regulation by alarmone ppGpp. Cell 2004; 117:299-310.

-Báez JL, Bolívar F, Gosset G: Determination of 3-deoxy-D-Arabino-heptulosonate 7-phosphate productivity and yield from glucose in Escherichia coli devoid of the glucose phosphotransferase transport system. Biotechnol Bioeng 2001;73:530-535.

-Báez-Viveros JL, Osuna J, Hernández-Chávez G, Soberón X, Bolívar F, Gosset G: Metabolic engineering and protein directed evolution increase the yield of L-phenylalanine synthesized from glucose in Escherichia coli. Biotechnol Bioeng 2004;87:516-524.

Bailey TL, Elkan C: Fitting a mixture model by expectation maximization to discover motifs in biopolymers. Proc 2nd Int Conf on ISMB. Menlo Park, AAAI Press, 1994, pp 28-36.

Bailey TL, Gribskov M: Combining evidence using p-values: application to sequence homology searches. Bioinformatics 1998;14:4854.

Baker MM, Gaal T, Gourse RL: Mechanisms of regulation of transcription initiation by ppGpp. II. Models for positive control based on properties of RNAP mutants and competition for RNAP. J Mol Biol 2001a;305:689702 .

- Baker MM, Gaal T, Josaitis CA, Gourse RL: Mechanisms of regulation of transcription initiation by ppGpp. I. Effects of ppGpp on transcription initiation in vivo and in vitro. J Mol Biol 2001b;305:673-688.
- Bolívar F, Rodríguez RL, Greene PJ, Betlach MC, Hyenecker HL, Boyer HW, Crosa JH, Falkow $\mathrm{S}$ : Construction and characterization of new cloning vehicles. II. A multipurpose cloning system. Gene 1977;2:95-113.

Cashel M, Gentry DR, Hernández VI, Vinella D: The stringent response; in Neidhardt FC (ed). Escherichia coli and Salmonella. Cellular and Molecular Biology. Washington, American Society for Microbiology, 1996, vol 1, pp 1458-1496.

Chatterji D, Ojha AK: Revisiting the stringent responses for ppGpp and starvation signaling. Curr Opin Microbiol 2001;4:160-165.

de Anda R, Lara A, Hernández V, HernándezMontalvo V, Gosset G, Bolìvar F, Ramírez T: Replacement of the glucose phosphotransferase transport system by galactose permease reduces acetate accumulation and improves process performance of Escherichia coli for recombinant protein production without impairment of growth rate. Metab Eng 2006;8:281-290.

Death A, Ferenci T: Between feast and famine: endogenous inducer synthesis in the adaptation of Escherichia coli to growth with limiting carbohydrates. J Bacteriol 1994;176: 5101-5107.

Ferenci T: Hungry bacteria - definition and properties of a nutritional state. Environ Microbiol 2001;3:605-609.

-Ferenci T: What is driving the acquisition of mutS and rpoS polymorphisms in Escherichia coli? Trends Microbiol 2003;11:457-461.

Flores N: Master Degree Thesis, Institute of Biotechnology, UNAM, México, 1995.
Flores N, de Anda R, Flores S, Escalante A, Hernández G, Martínez A, Ramírez OT, Gosset G, Bolívar F: The role of pyruvate oxidase in Escherichia coli strains lacking the phoshphoenolpyruvate:carbohydrate phosphotransferase system. J Mol Microbiol Biotechnol 2004;8:209-221.

-Flores N, Flores S, Escalante A, de Anda R, Leal L, Malpica R, Geogellis D, Gosset G, Bolívar F: Adaptation for fast growth on glucose by differential expression of central carbon metabolism and gal regulon genes in an Escherichia coli strain lacking the phosphoenolpyruvate:carbohydrate phosphotransferase system. Metab Eng 2005;7:70-87.

Flores N, Xiao J, Berry A, Bolívar F, Valle F: Pathway engineering for the production of aromatic compounds in Escherichia coli. Nat Biotechnol 1996;14:620-623.

Flores S, Flores N, de Anda R, González A, Escalante A, Sigala JC, Gosset G, Bolívar F: Nutrient scavenging stress response in an Escherichia coli strain lacking the phosphoenolpyruvate:carbohydrate phosphotransferase system, as explored by gene expression profile J Mol Microbiol Biotechnol 2005;10: 51-63.

Flores S, Gosset G, Flores N, de Graaf AA, Bolívar F: Analysis of carbon metabolism in Escherichia coli strains with an inactive phosphotransferase system by ${ }^{13} \mathrm{C}$ labeling and NMR spectroscopy. Metab Eng 2002;4:124-

137.
Fried MG, Hudson JM: DNA looping and lac repressor-CAP interaction. Science 1996;274: 1930-1931. 
-Gentry D, Bengra C, Ikehara K, Cashel M: Guanylate kinase of Escherichia coli K12. J Biol Chem 1993;268:14316-14321.

- Gosset G, Yong-Xiao J, Berry A: A direct comparison of approaches for increasing carbon flow to aromatic biosynthesis in Escherichia coli. J Ind Microbiol 1996;17:47-52.

- Gosset G, Zhang Z, Nayyar S, Cuevas WA, Saier $\mathrm{MH}$ Jr: Transcriptome analysis of Crp-dependent catabolite control of gene expression in Escherichia coli. J Bacteriol 2004;186: 3516-3524.

Hengge-Aronis R: Regulation of gene expression during entry into stationary phase; in Neidhardt FC (ed): Escherichia coli and Salmonella. Cellular and Molecular Biology. Washington, American Society for Microbiology, 1996, vol 1, pp 1497-1512.

-Hengge-Aronis R: Signal transduction and regulatory mechanisms involved in control of the sigma S (RpoS) subunit of RNA polymerase. Microbiol Mol Biol Revs 2002;66: 373-395.

-Hua Q, Yang C, Oshima T, Mori H, Shimizu K: Analysis of gene expression in Escherichia coli in response to changes of growth-limiting nutrient in chemostat cultures. Appl Environ Microbiol 2004;70:2354-2366.

- Jishage M, Kvint K, Shingler V, Nystrom T: Regulation of sigma factor competition by the alarmone ppGpp. Gene Dev 2002;16:12601270.

- King T, Seeto S, Ferenci T: Genotype-by-environment interactions influencing the emergence of rpoS mutations in Escherichia coli populations. Genetics 2006;172:2071-2079.

Kvint K, Farewell A, Nyström T: RpoS-dependent promoters required guanosine tetraphosphate for induction even in the presence of high levels of sigma S. J Biol Chem 2000; 275:14795-14798.
Lange R, Hengge-Aronis R: The cellular concentration of the sigma subunit of RNA polymerase in Escherichia coli is controlled at the levels of transcription, translation and protein stability. Gene Dev 1994;8:1600-1612.

Lange R, Fisher D, Hengge-Aronis R: Identification of transcriptional start sites and the role of ppGpp in the expression of rpoS, structural gene for the sigma $S$ subunit of RNA polymerase in Escherichia coli. J Bacteriol 1995; 177:4676-4680.

Lengeler JW, Drows G, Schleggel HG: Biology of Prokaryots. New York, Blackwell Science, 1999, pp 505-509.

Livak K, Schmittgen TD: Analysis of relative gene expression data using real-time quantitative PCR and the 2(-Delta Delta C(T))method. Methods 2001;25:402-408.

Maeda H, Fujita N, Ishihama A: Competition among seven Escherichia coli sigma subunits: relative binding affinities to the core RNA polymerase. Nucleic Acids Res 2000; 28:3497-3503.

Notley-McRobb L, Ferenci T: Induction of RpoS dependent functions in glucose limited continuous culture: what level of nutrient limitation induces the stationary phase of Escherichia coli? J Bacteriol 1996;178:14651468.

Notley-McRobb L, King T, Ferenci T, rpoS mutations and loss of general stress resistance in Escherichia coli populations as a consequence of conflict between competing stress responses. J Bacteriol 2002;184:806-811.

Postma PW, Lengeler JW, Jacobson GR: Phos phoenolpyruvate: carbohydrate phosphotransferase systems; in Neidhardt FC (ed): Escherichia coli and Salmonella. Cellular and Molecular Biology. Washington, American Society for Microbiology, 1996, vol 1, pp 1149-1174.
Rahman M, Hassan MR, Oba T, Shimizu K: Effect of rpoS gene knockout inactivation on the metabolism of Escherichia coli during exponential growth phase and early stationary phase based on gene expressions, enzyme activities and intracellular metabolite concentrations. Biotechnol Bioeng 2006;94:585595.

Raghunathan A, Palsson B: Scalable method to determine mutations that occur during adaptative evolution of Escherichia coli. Biotechnol Lett 2003;25:435-441.

Saier MH: Vectorial metabolism and the evolution of the transport systems. J Bacteriol 2002;182:5029-5035.

Semsey S, Virnik K, Adhya S: A gamut of loops: meandering DNA. Trends Biochem Sci 2005; 30:334-341.

Simons RW, Houman F, Klecker N: Improved single and multicopy lac-based cloning vector for protein and operon fusions. Gene 1987;53:85-96.

-Teich A, Meyer S, Lin HY, Andersson L, Enfers SO, Neubauer P: Growth rate related concentration changes of the starvation response regulators sigmaS and ppGpp in glucose limited fed-batch continuous cultures of Escherichia coli. Biotechnol Prog 1999;15:123129.

Ueguchi C, Misonov N, Mizuno T: Negative control of rpoS expression by phosphoenolpyruvate:carbohydrate phosphotransferase system in Escherichia coli. J Bacteriol 2001;183: 8499-8507.

Wagner R: Regulation of ribosomal RNA synthesis in Escherichia coli: effects of the global regulator ppGpp. J Mol Microbiol Biotech 2002;4:331-340.

-Weber H, Polen T, Heuveling J, Wendisch VF, Hengge-Aronis R: Genome wide analysis of the general stress response network in Escherichia coli: sigmaS-dependent genes, promoters and sigma factor selectivity. J Bacteriol 2005; 187:1591-1603. 